$\mathrm{C6 \textrm {q }}$

no. $79-22$
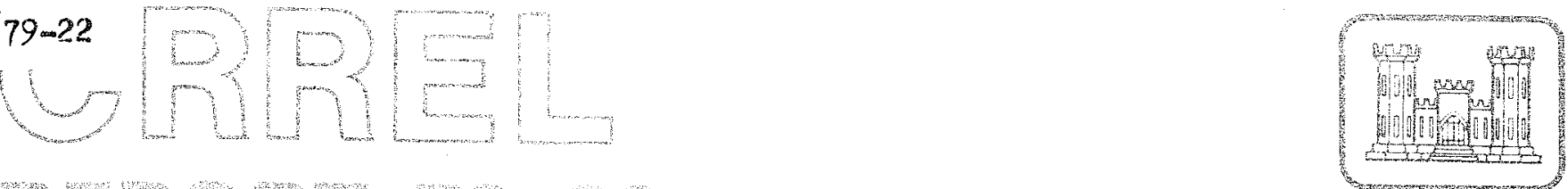

W

\title{
Crystal alignments in the fast ice of arctic Alaska
}

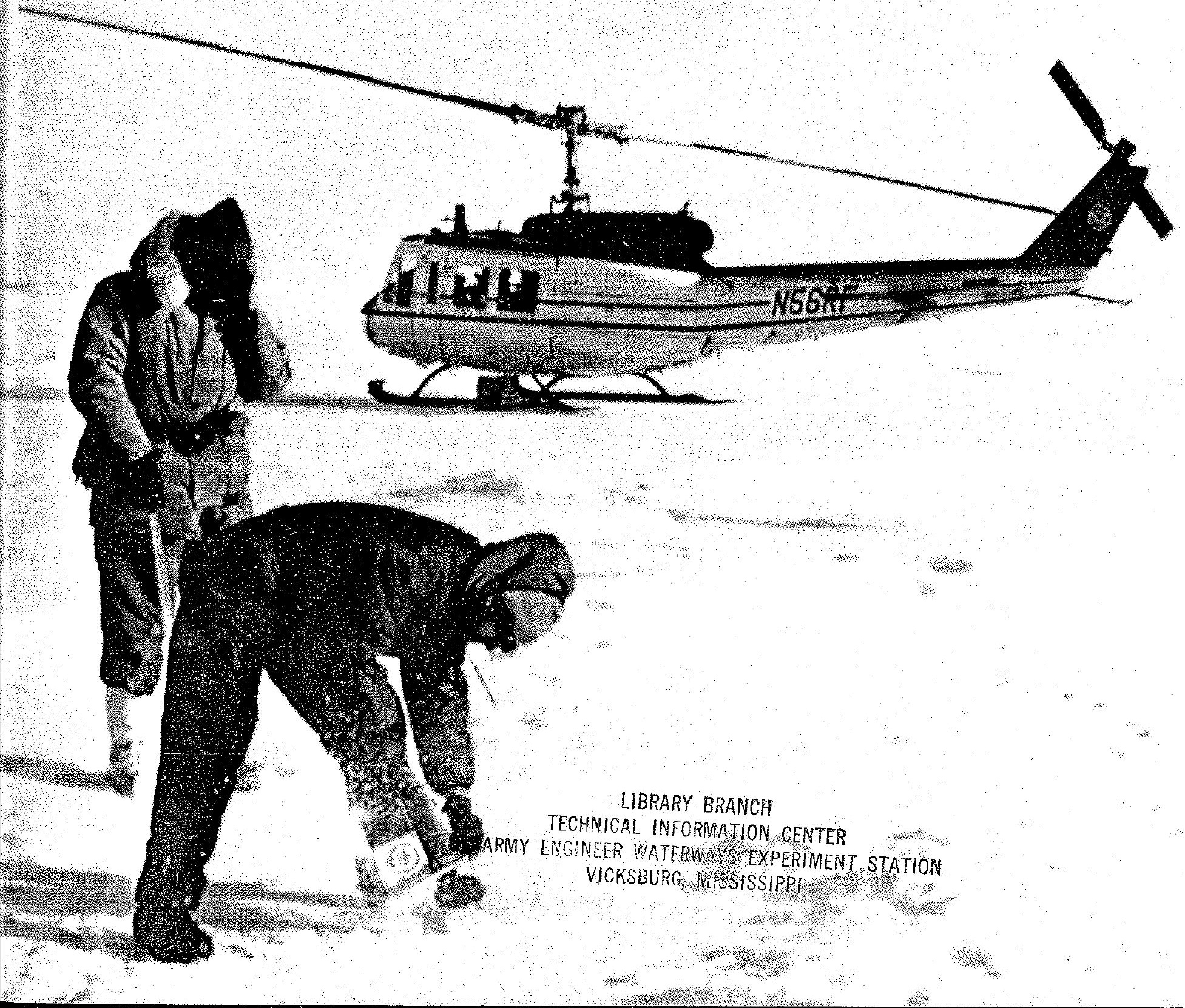




\section{CRREL Report 79-22}

\section{Crystal alignments in the fast ice of arctic Alaska}

W.F. Weeks and A.J. Gow

October 1979

Prepared for

NATIONAL SCIENCE FOUNDATION

WASHINGTON, D.C.

and

NATIONAL OCEANIC AND ATMOSPHERIC ADMINISTRATION

BOULDER, COLORADO

By

UNITED STATES ARMY

CORPS OF ENGINEERS

COLD REGIONS RESEARCH AND ENGINEERING LABORATORY

HANOVER, NEW HAMPSHIRE, U.S.A. 
Unclassified

SECURITY CLASSIFICATION OF THIS PAGE (When Data Entered)

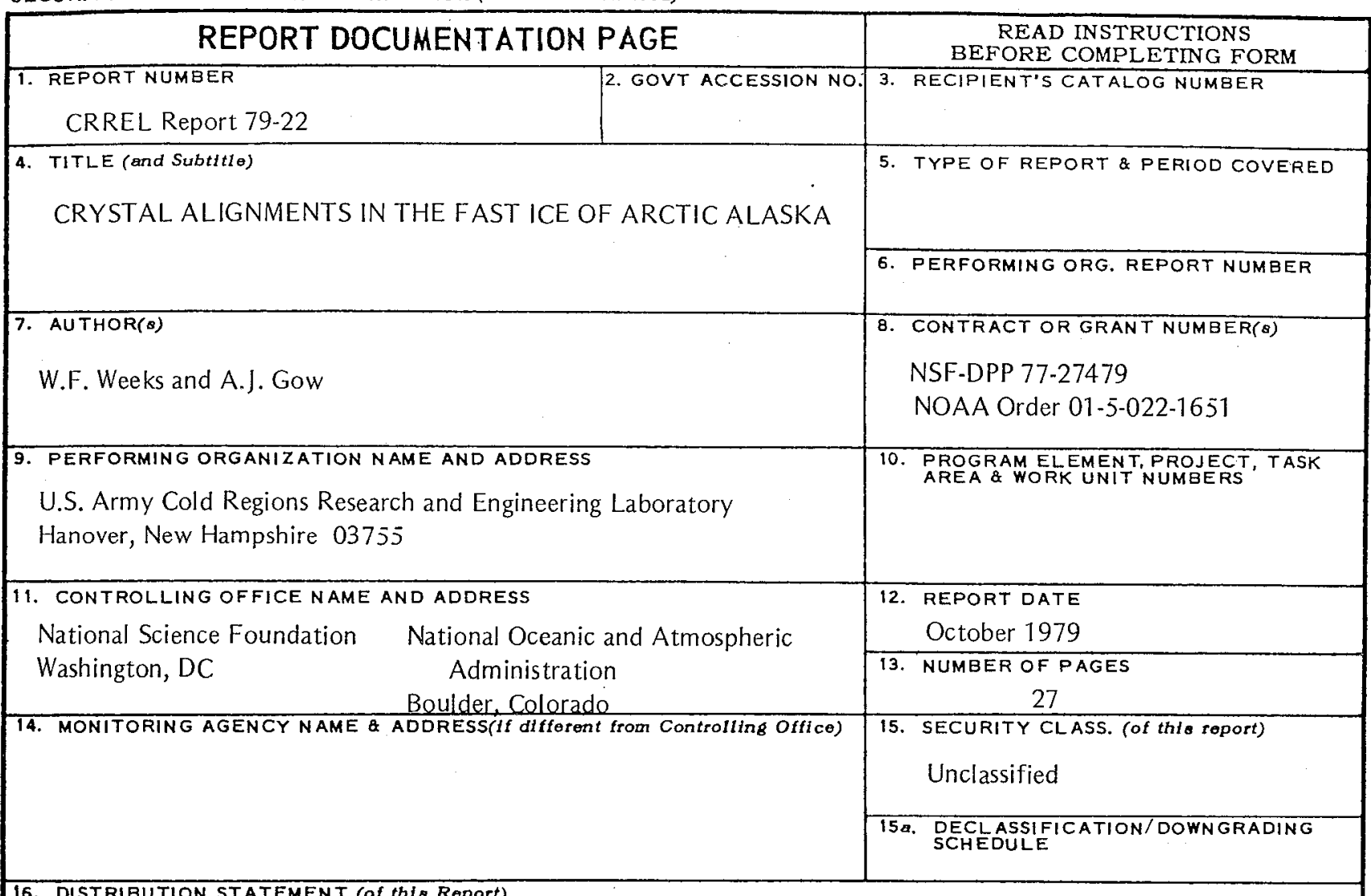

16. DISTRIBUTION STATEMENT (of this Report)

Approved for public release; distribution unlimited.

17. DISTRIBUTION ST ATEMENT (of the abstract onterod In Block 20, if different from Report)

18. SUPPLEMENTARY NOTES

19. KEY WORDS (Continue on reverse side if necessary and identlfy by block number)

Beaufort Sea

Chukchi Sea

Pack ice

Crystal growth

Sea ice

Crystal structure

lce

20. ABSTAACT (Continue ace reverae sicte if necoseany and identify by block number)

Field observations at 60 sites located in the fast or near-fast ice along a $1200-\mathrm{km}$ stretch of the nor th coast of Alaska between Bëring Strait and Barter Island have shown that the great majority of the ice samples (95\%) exhibit striking c-axis alignments within the horizontal plane. Such alignments were usually well developed by the time the ice was $50 \mathrm{~cm}$ thick and in some cases when the ice was $20 \mathrm{~cm}$ thick. In all cases the degree of preferred orientation increased with depth in the ice. Representative standard deviations around a mean direction in the horizontal plane are commonly less than $\pm 10^{\circ}$ for samples collected near the bottom of the ice. The general patterns of the alignments support a correlation between the preferred c-axis direction and the current direction at the ice/water interface. A comparison 


\section{Abstract (cont'd).}

between $c$-axis alignments and spot current measurements made at 42 locations shows that the most frequent current direction coincides with the mean c-axis direction. Such alignments are believed to be the result of geometric selection with the most favored orientation being that in which the current flows normal to the (0001) plates of ice that compose the dendritic sea ice/sea water interface. 


\section{PREFACE}

This report was prepared by Dr: W.F. Weeks, Claciotogist, and Dr. A.J. Gow, Research Geologist, Snow and Ice Branch, Research Division, U.S. Army Cold Regions Research and Engineering Laboratory. The research effort was jointly supported by the Glaciology Program of the Division of Polar Programs of the National Science Foundation and by the Outer Continental Shelf Enviromental Assessment Program (OCSEAP). OCSEAP is a multiyear program responding to needs of petroleum development of the Alaskan continental shelf which is supported by the Bureau of Land Management and managed by the National Oceanic and Atmospheric Administration through interagency agreement. Logistic support was also received from the Naval Arctic Research Laboratory.

The authors would particularly like to thank their co-investigator $\mathrm{H}$. Kohnen for his schnapps; the members of their flight crews-J. Barnhill, E. Feldt and B. Points - for their skill; T. Flesher, Dan Brooks and Terry Hall for logistic support; E. Thornton for the loan of the current meter; and R. Cameron and G. Weller for continued encouragement. R. Paquette and S. Martin served as reviewers of the final manuscript. A major portion of the work on this report was accomplished while Dr. Weeks was ONR Professor of Arctic Marine Science at the Naval Postgraduate School. 


\section{CONTENTS}

\begin{tabular}{|c|c|}
\hline \\
\hline & 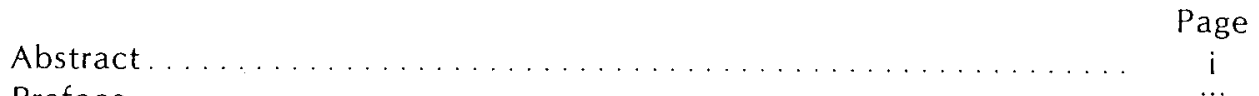 \\
\hline Preface & iii \\
\hline$\therefore \ldots \ldots \ldots$ & \\
\hline tion $\ldots \ldots \ldots \ldots \ldots \ldots \ldots \ldots \ldots \ldots \ldots$ & \\
\hline 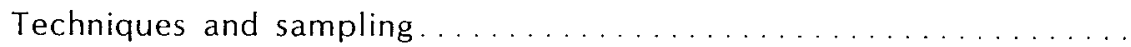 & \\
\hline e & \\
\hline ignments . . . . . . & \\
\hline 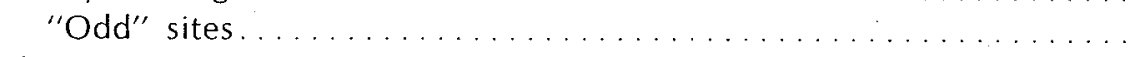 & 13 \\
\hline . & 15 \\
\hline$\ldots \ldots \ldots \ldots \ldots \ldots \ldots \ldots \ldots \ldots$ & \\
\hline & \\
\hline endix A: Current observations & \\
\hline
\end{tabular}

\section{ILLUSTRATIONS}

Figure

1. General location of the fast ice areas that were sampled.........

2. Sample site locations, mean c-axis aligriments and instantaneous current directions determined in the vicinity of Kotzebue Sound.

3. Schmidt net plots of individual c-axis orientations from three sites showing strong $\mathrm{C}$-axis alignments in the Kotzebue Sound region....

4. A series of horizontal thin sections and Schmidt net plots showing the rapid development of a strong $\mathrm{C}$-axis alignment within the horizontal plane at Site 78-3 in Kotzebue Sound.

5. Sample site locations, mean c-axis alignments and instantaneous current directions determined along the Chukchi Sea coast.

6. Four representative examples of aligned crystal orientations observed along the coasts of the Chukchi and Beaufort Seas.

7. Sample site locations, mean c-axis alignments and instantaneous current directions determined in the vicinity of Point Barrow. .....

8. Comparison of crystal orientation data collected in April 1978 and March 1979 at identical and similar sites along the Chukchi coast near Point Barrow.

9. Sample site locations, mean c-axis alignments and instantaneous current directions determined along the coast of the Beaufort Sea. .

10. Examples of sea ice fabrics that show either random or weak c-axis alignments within the horizontal plane.

11. Schmidt net plots of individual c-axis orientations at Site $79-3 \ldots \ldots$

12. Histograms showing the relative frequency of different deviations. .

13. Histogram showing the relative frequency of different current direc-

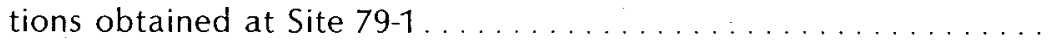

\section{TABLES}

Table

1. Summary of crystal orientation information. ............. 


\section{SUMMARY}

Field observations at 60 sites located in the fast or near-fast ice along a $1200-\mathrm{km}$ stretch of the north coast of Alaska between Bering Strait and Barter Island have shown that the great majority of the ice samples (95\%) exhibit striking c-axis alignments within the horizontal plane. Such alignments were usually well developed by the time the ice was $50 \mathrm{~cm}$ thick and at some locations when the ice was $20 \mathrm{~cm}$ thick. In all cases the degree of preferred orientation increased with depth in the ice. Representative standard deviations around a mean direction in the horizontal plane are commonly less than $\pm 10^{\circ}$ for samples collected near the bottom of the ice. At a given site the mean c-axis direction $\left(\bar{X}_{0}\right)$ may vary somewhat with vertical location in the ice sheet. These variations are usually less than $20^{\circ}$ and do not show clear-cut trends. The c-axis alignments in the near-shore region are, in general, parallel to the coast, with strong alignments occurring in the lagoon systems between the barrier islands and the coast, and seaward of the barrier islands. In passes between islands and in entrances such as the opening to Kotzebue Sound, the alignment is parallel to the channel. Only limited observations are available farther seaward over the inner (10-50 $\mathrm{m}$ isobaths) and outer (50 $\mathrm{m}$ isobath to shelf break) shelf regions. These indicate NE-SW and E-W alignments, respectively, in the Beaufort Sea north of Prudhoe Bay.

The general patterns of the alignments support the correlation between the preferred c-axis direction and the current direction at the ice/water interface suggested by Weeks and Gow (1978). Further support for this hypothesis is provided by the fact that observations in the Chukchi Sea just off Barrow give excellent agreement between $\left(\bar{X}_{0}\right)$ at the bottom of the ice sheet $\left(48^{\circ}\right.$ true) and the mean current direction ( 7 hour average) just below the ice/water interface at the same site $\left(52^{\circ}\right.$ true). A comparison between $\mathrm{c}$-axis alignments and spot current measurments made at 42 locations shows that the most frequent current direction coincides with $\left(\bar{X}_{0}\right)$. Similarly if only $\left(\bar{X}_{0}\right)$ values determined in the near-shore region are considered, the most frequent deviation is $10^{\circ}$ or less between $\left(\bar{X}_{0}\right)$ and the trend of the adjacent shoreline, which is presumably parallel to the prevailing longshore currents. The c-axis alignments are believed to be the result of geometric selection, with the most favored orientation being that in which the current flows normal to the (0001) plates of ice that compose the dendritic sea ice/sea water interface.

The instantaneous current observations taken in conjunction with the ice sampling program suggest southwest near-shore currents along the Chukchi coast from southwest of Point Lay to southwest of the Rogers-Post Monument. In the vicinity of Barrow all currents measured along the Chukchi coast were toward the northwest. Current directions along the Beaufort coast in the near-shore region were generally parallel to the coast, with $45 \%$ of the observations indicating currents toward the east and $55 \%$ currents toward the west. 


\title{
CRYSTAL ALIGNMENTS IN THE FAST ICE OF ARCTIC ALASKA
}

\author{
W.F. Weeks and A.J. Gow
}

\section{INTRODUCTION}

In a recent paper (Weeks and Gow 1978) we described strongly developed horizontal c-axis (crystallographic) alignments that were observed within a triangular near-shore region of fast sea ice within an area of roughly $1400 \mathrm{~km}^{2}$ located in the Beaufort Sea northeast of Prudhoe Bay, Alaska. We also summarized earlier observations on this phenomenon made by American, Canadian and Soviet observers. Based on these combined observations we suggested that such alignments are the common situation in fast or near-fast sea ice and that the preferred $c$-axis direction is a reflection of the current direction at the sea ice/seawater interface. The alignments were believed to be caused by the current affecting the transfer of impurity (salt) at the growing interface in such a manner that crystals with their c-axes aligned parallel to the current gain a slight growth advantage. The crystals oriented closest to the favored direction are, therefore. able to grow slightly ahead of their less favored neighbors and encroach upon their territory at the interface. Ultimately the less favored crystals are eliminated by being completely cut off from contact with the melt.
This report is an extension of our previous study in that we were able between 29 March and 25 April 1978 to sample the internal structure of the sea ice at 35 additional sites located along the coast of arctic Alaska starting roughly $120 \mathrm{~km}$ northeast of the Bering Strait in the Chukchi Sea and extending to roughly $75 \mathrm{~km}$ west of Kaktovik (Barter Island) in the Beaufort Sea. We were also able to revisit three of these sites in March 1979. The length of coastline covered by the samples was approximately 1200 $\mathrm{km}$. The general regions sampled are shown in Figure 1, which gives the locations of the more detailed maps presented later. We had initially hoped to be able to collect samples all along the coast between Bering Strait and the Canadian border. However, a combination of mechanical problems with our principal means of transportation (helicopter) and bad flying weather prevented this. Nevertheless, we were able to cover a great deal of real estate and, although our coverage could hardly be called "dense," we believe that the results are sufficiently consistent to leave one with little doubt concerning what would have been found in the areas we were unable to sample. 


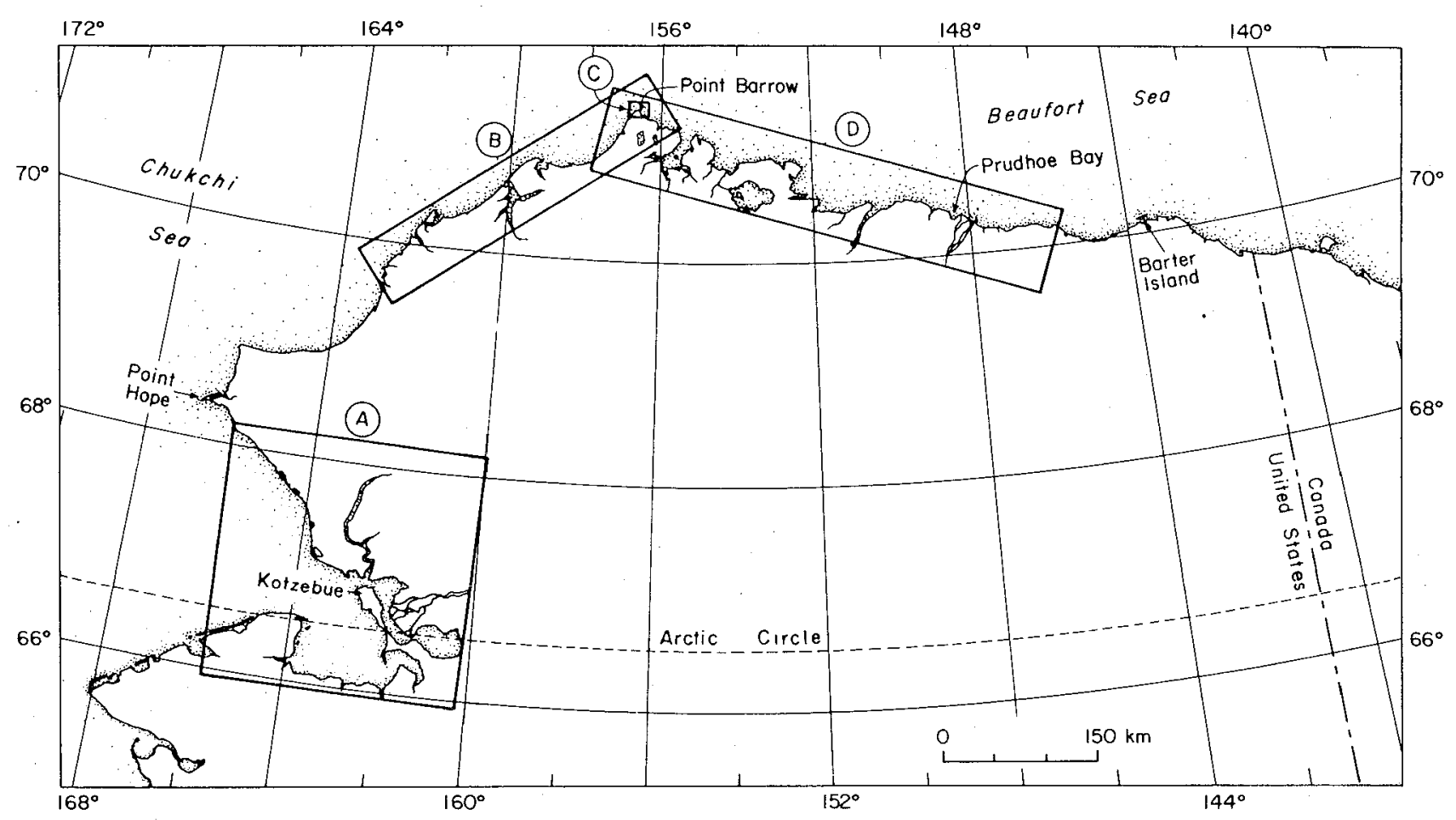

Figure 1. General location of the fast ice areas that were sampled. The detailed maps are presented later in. the paper as Figure 2(A), Figure 5(B), Figure $7(C)$, and Figure $9(D)$.

\section{TECHNIQUES AND SAMPLING}

A detailed description of the techniques we utilized is given in Weeks and Cow (1978). We will only provide a brief summary here. At each site we initially cut a $30-\times 30-\mathrm{cm}$-wide and $90-\mathrm{cm}$ deep block of ice using a chain saw. The stratigraphy of the block (slush layers, etc.) was described and the bottom $20 \mathrm{~cm}$ was retained to use in the preparation of thin sections. The ice below $1 \mathrm{~m}$ was sampled using a CRREL 7.8-cm-diameter ice corer so that the crystal orientation could be determined at the base of the ice sheet. Because the crystal orientations observed at the bottom of the cores did not usually differ appreciably from the orientations observed at the base of the block, we will commonly report the latter as they are based on a larger ice sample. The thin sections were prepared and the crystal orientations were determined using standard petrographic and universal stage tecniques. At each site we also measured the instantaneous current velocity just beneath the ice using a MarshMcBirney electromagnetic current meter. Also determined were the total ice thickness and the ice temperature and salinity profiles. These were utilized in a study of the directional electrical resistivity of the ice. This work will be discussed in a separate paper by our co-worker, Dr. $\mathrm{H}$. Kohnen of the University of Münster.

In selecting our sample sites we attempted to space our samples out along the coastline. We also included samples from some lagoons and lagoonal inlets at locations where the water was known to be saline. The coordinates of the sampling sites were determined from the VLF "Global" navigational system on board the helicopter. On arrival at the approximate site, we examined the ice and landed on an area where the surface was flat and the nearest pressure ridges were at least $30 \mathrm{~m}$ away. Because the ice surface was commonly covered with 10 to $20 \mathrm{~cm}$ of rather dense snow, we had no way of "prejudging" the suitability of the ice until we had actually collected the ice block. We also had no exact way of determining the movement history of the ice we sampled. It was all fast at the time it was sampled and in general we believe that at most sites it had probably been fast since early in the winter. In some areas (Kotzebue Sound and the Beaufort Sea coast) samples were collected at some distance from the shore where 
the fast ice belt was quite wide. At other locations (for instance, the Chukchi coast) the sampling sites were very near shore as the fast ice belt was extremely narrow.

\section{OBSERVATIONS}

In presenting our field observations we will start at our southwesternmost point (located north of Shishmaref Inlet) and work our way around the coast to Camden Bay. The sites have been numbered in this sequence. The results of the field measurements are given in Table 1 . In the map presentations the dot indicates the location of the sample site, the line through the dot specifies the average $c$-axis direction as determined from the ice thin sections, and the arrow gives the direction of the instantaneous current measured under the ice. When no arrow is given there was no discernible current. When the bar is missing there was no appreciable crystal alignment. Because mean c-axis alignment directions
$\left(\bar{X}_{0}\right)$ are axial they can be specified equally well by $\left(\bar{X}_{0}\right)$ or by $\left(\bar{X}_{0}\right)+180^{\circ}$. In Table 1 we have used the $\left(\bar{X}_{0}\right)$ value that is closest to the observed current direction when coincident current measurements were made. Note also that the 78 in Site 78-1, 78-2, etc. indicates that the sample was collected during the late winter of 1978. In some of the maps we have left the 77's and 78 's off because of lack of space. It is easily possible to determine which sites are 77 's and which are 78's by referring to the figure captions and to Table 1.

\section{Crystal alignments}

Figure 2 shows the results from the general area of Kotzebue Sound. All sites showed c-axis alignments (Figure 3 gives representative examples) with the exception of Site 78-9 at Cape Thompson. We will discuss the "odd" sites as a group later in the paper. The c-axis alignments formed quickly and at some sites (Fig. 4) were strongly developed by the time the ice was 20 $\mathrm{cm}$ thick. The $\mathrm{c}$-axes were aligned parallel to the

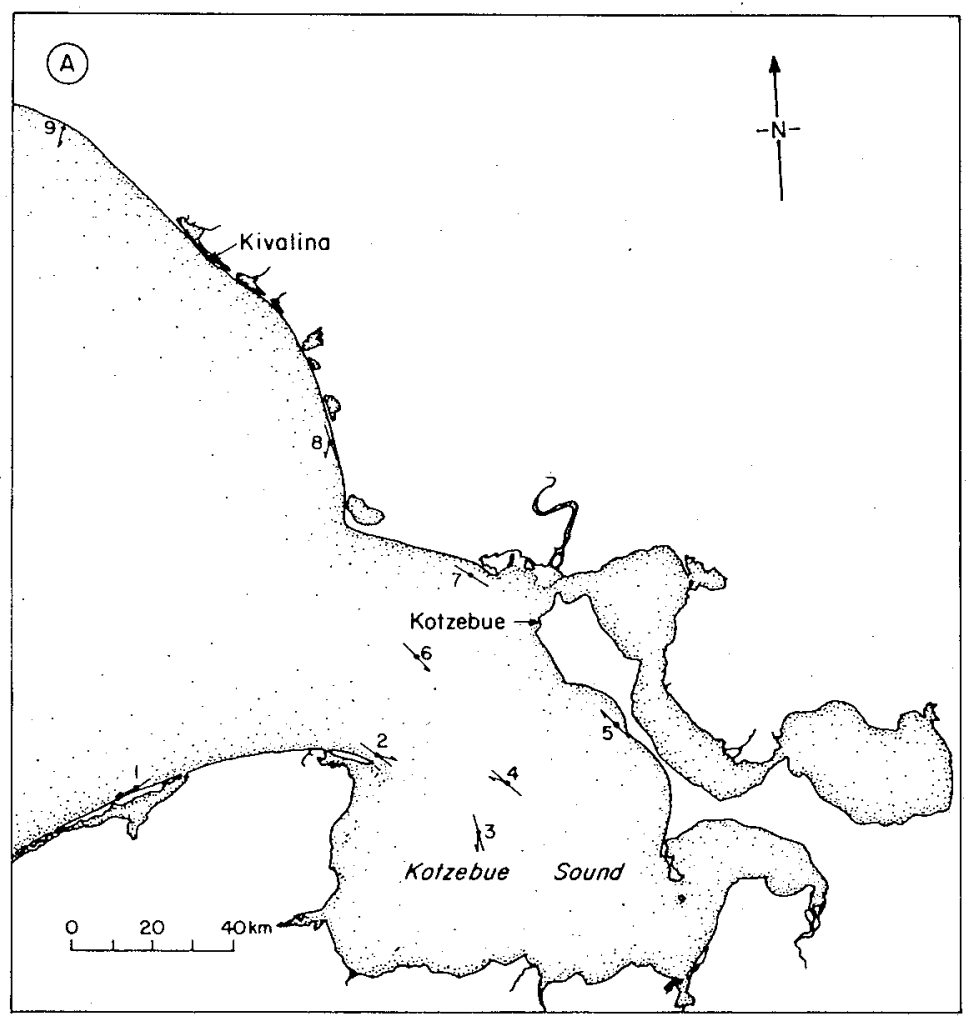

Figure 2. Sample site locations (numbered dots), mean c-axis alignments (bars) and instantaneous current directions (arrows) determined in the vicinity of Kotzebue Sound. All sites are 78 sites. 

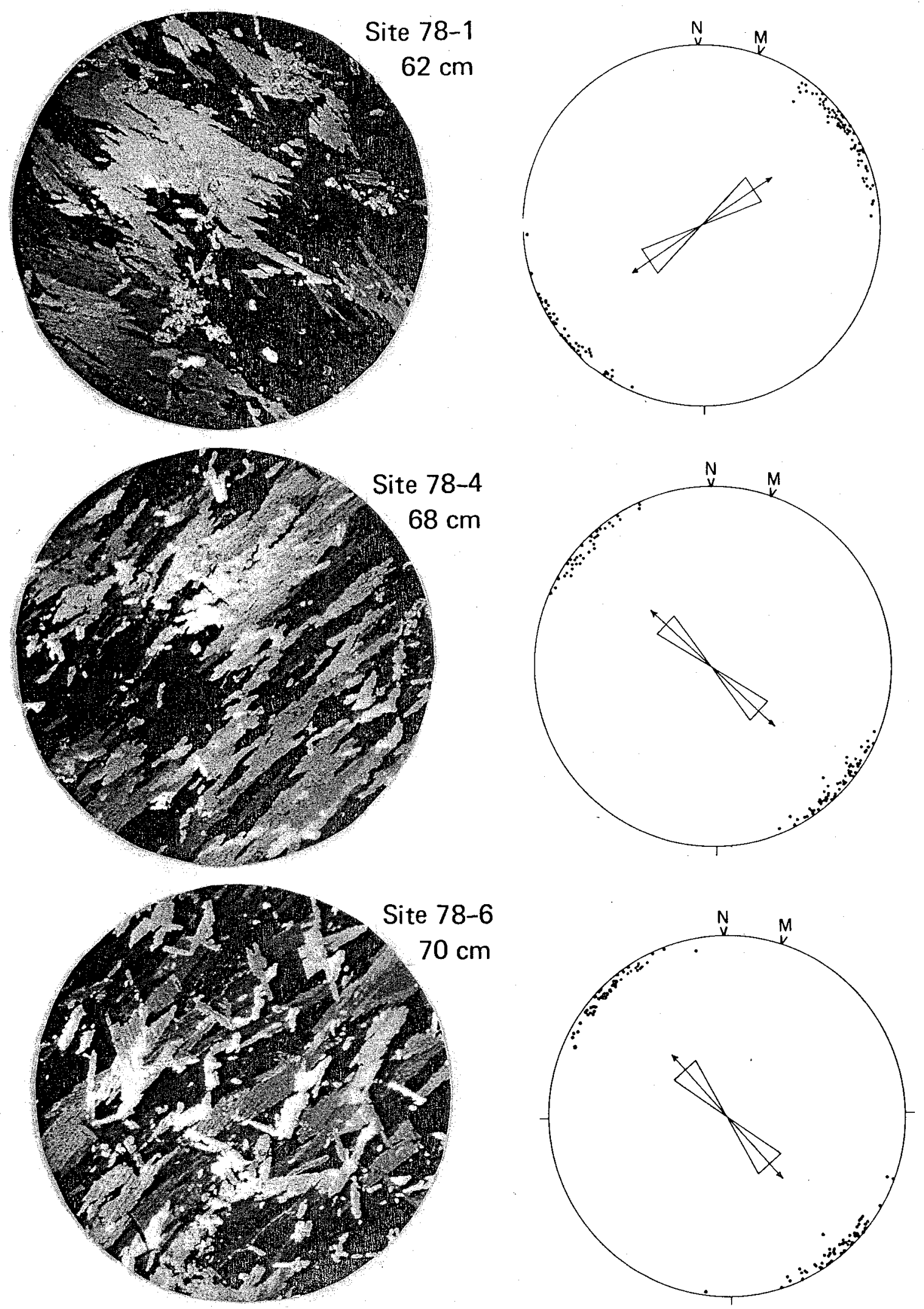

Figure 3. Schmidt net plots of individual c-axis orientations (dots) from three sites showing strong $c$-axis alignments in the Kotzebue Sound region (see Figure 2 for site locations). 

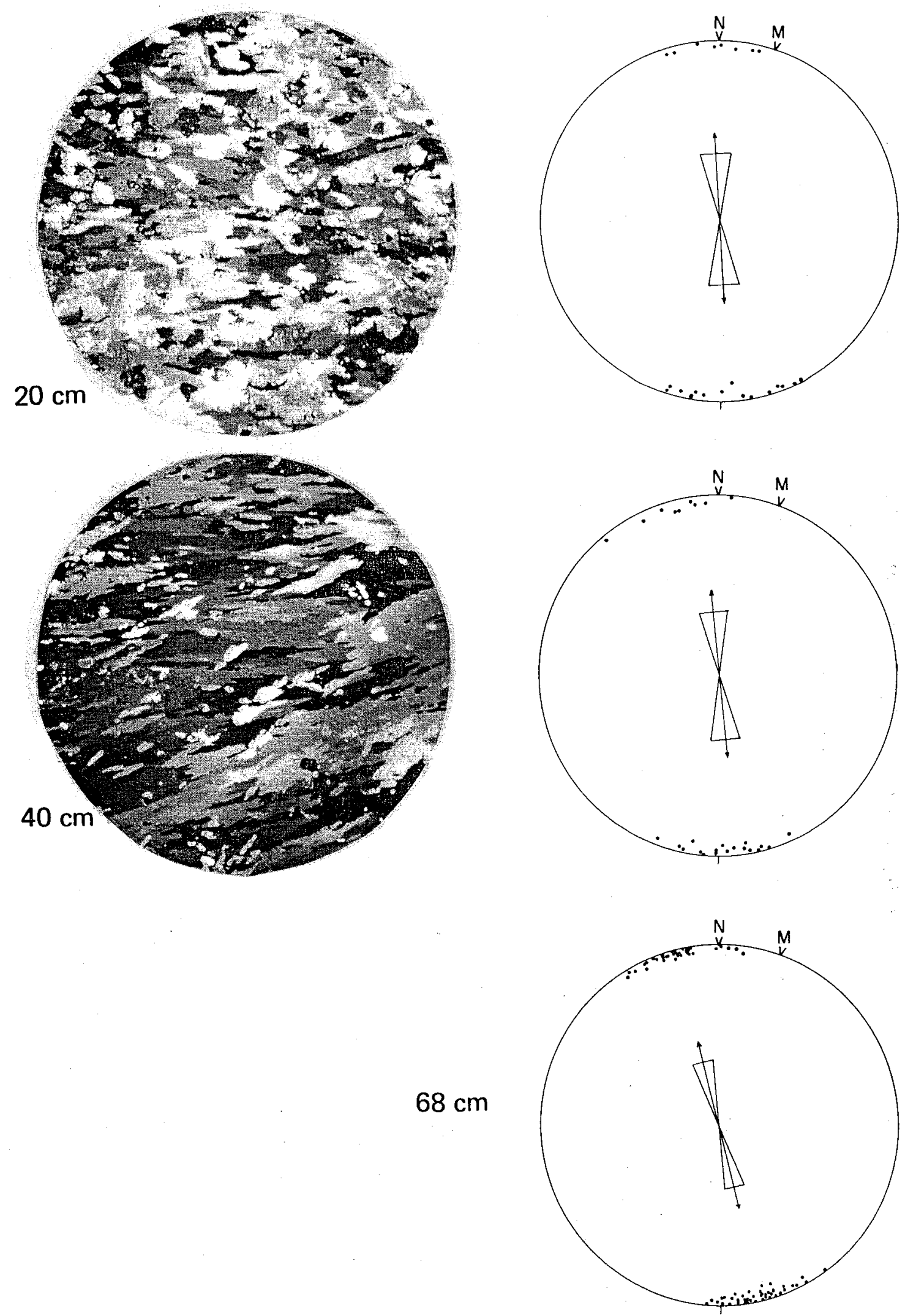

Figure 4. A series of horizontal thin sections and Schmidt net plots showing the rapid development of a strong c-axis alignment within the horizontal plane at Site 78-3 in Kotzebue Sound (see Figure 2 for site location). 
Table 1. Summary of crystal orientation information.

\begin{tabular}{|c|c|c|c|c|c|c|c|c|c|c|c|c|}
\hline Site & Location & $\operatorname{Lat}(N)$ & Long(W) & $\begin{array}{c}\text { Sample } \\
\text { type }\end{array}$ & $\begin{array}{c}\text { Sample } \\
\text { depth } \\
(\mathrm{m})\end{array}$ & $\begin{array}{l}\text { Ice } \\
\text { thick- } \\
\text { ness } \\
(m)\end{array}$ & $\begin{array}{l}\text { No. of } \\
\text { crystals }\end{array}$ & $\begin{array}{c}\mathrm{S}_{n} \\
\text { Circular } \\
\text { variance }\end{array}$ & $\begin{array}{r}s_{a} \\
S t d \\
d e v \\
\text { (deg) } \\
\end{array}$ & $\begin{array}{c}\bar{X}_{0 .} \text { Avg. } \\
\text { C-axis } \\
\text { orient } \\
\text { (otrue) }\end{array}$ & $\begin{array}{c}\text { Current } \\
\text { direction } \\
\left({ }^{\circ} \text { true }\right)\end{array}$ & $\begin{array}{l}\text { Current } \\
\text { speed } \\
(\mathrm{m} / \mathrm{s})\end{array}$ \\
\hline 78-1 & $\mathrm{N}$ of Shishmaref Inlet & $62^{\circ} 29.7^{\prime}$ & $165^{\circ} 00.2^{\prime}$ & Block & 0.62 & 0.99 & 109 & 0.026 & 13 & 235 & 242 & 0.06 \\
\hline $78-2$ & Cape Espenberg & $66^{\circ} 34.9^{\prime}$ & $163^{\circ} 35$ & Block & 0.60 & 0.97 & 112 & 0.023 & 12 & 127 & 108 & 0.03 \\
\hline $78-3$ & Kotzebue Sound & $66^{\circ} 23.4^{\prime}$ & $163^{\circ} 01^{\prime}$ & Block & 0.68 & 0.94 & 78 & 0.013 & 9 & 167 & 184 & 0.02 \\
\hline $78-4$ & Kotzebue Sound & $66^{\circ} 30 . t^{\prime}$ & $162^{\circ} 49.1^{\prime}$ & Block & 0.68 & 0.97 & 91 & 0.018 & 11 & 314 & 294 & 0.06 \\
\hline $78-5$ & Kotzebue Sound & $66^{\circ} 38^{\prime}$ & $162^{\circ} 09.7^{\prime}$ & Block & 0.57 & 0.87 & 128 & 0.043 & 17 & 315 & 316 & 0.02 \\
\hline $78-6$ & Kotzebue Entrance & $66^{\circ} 48.2^{\prime}$ & $163^{\circ} 20^{\prime}$ & Block & 0.70 & 0.79 & 103 & 0.028 & 14 & 140 & 136 & 0.02 \\
\hline $78-7$ & $W$ of Sheshalik & $66^{\circ} 59.7^{\prime}$ & $162^{\circ} 59.4^{\prime}$ & Block & 0.62 & 1.03 & 117 & 0.188 & 37 & 124 & - & 0.00 \\
\hline $78-8$ & Cape Krusenstern & $67^{\circ} 18.8^{\prime}$ & $163^{\circ} 49^{\prime}$ & Block & 0.70 & 0.89 & 56 & 0.075 & 23 & 161 & 198 & 0.02 \\
\hline $78-9$ & Cape Thompson & $68^{\circ} 05^{\prime}$ & $165^{\circ} 27.6^{\prime}$ & Block & 0.62 & 1.10 & 121 & 0.449 & 63 & - & 197 & 0.02 \\
\hline $78-10$ & SW of Pt. Lay & $69^{\circ} 30.1^{\prime}$ & $163^{\circ} 14.7^{\prime}$ & Block & 0.84 & 1.33 & 71 & 0.031 & 14 & 142 & 176 & 0.05 \\
\hline $78-11$ & SW of Icy Cape & $69^{\circ} 58.3^{\prime}$ & $162^{\circ} 43.6^{\prime}$ & Block & 0.66 & 1.44 & 75 & 0.072 & 22 & 220 & 263 & 0.02 \\
\hline $78-12$ & SW of Wainwright & $70^{\circ} 27.3^{\prime}$ & $160^{\circ} 33.8^{\prime}$ & Block & 0.74 & 1.51 & 77 & 0.162 & 34 & 242 & 292 & 0.04 \\
\hline $78-13$ & $W$ of Pt. Franklin & $70^{\circ} 51.6^{\prime}$ & $159^{\circ} 24^{\prime}$ & Block & 0.87 & 1.45 & 68 & 0.029 & 14 & 234 & 231 & 0.04 \\
\hline $78-14$ & Peard Bay & $70^{\circ} 52.1^{\prime}$ & $157^{\circ} 58^{\prime}$ & Block & 0.55 & 1.29 & 77 & 0.021 & 12 & 233 & 260 & 0.04 \\
\hline $78-15$ & SW of Monument & $71^{\circ} 03.4^{\prime}$ & $157^{\circ} 18^{\prime}$ & Block & 0.87 & 1.50 & 64 & 0.014 & 10 & 219 & 232 & 0.05 \\
\hline $78-16$ & Barrow (Chukchi) & $71^{0} 19.2^{\prime}$ & $156^{\circ} 43.5^{\prime}$ & Block & 0.90 & 1.69 & 82 & 0.049 & 18 & 55 & 26 & 0.07 \\
\hline $78-17$ & Barrow (Chukchi) & $71^{\circ} 20.4^{\prime}$ & $156^{\circ} 38.7^{\prime}$ & Block & 0.88 & 1.68 & 58 & 0.010 & 8 & 71 & 36 & 0.06 \\
\hline $78-18$ & Barrow (Chukchi) & $71^{\circ} 21.3^{\prime}$ & $156^{\circ} 34.2^{\prime}$ & Block & 0.78 & 1.63 & 74 & 0.017 & 11 & 69 & 53 & 0.02 \\
\hline $78-19$ & Barrow (Beaufort) & $71^{\circ} 22.3^{\prime}$ & $156^{\circ} 22.7^{\prime}$ & Block & 1.65 & 1.70 & 20 & 0.031 & 14 & 138 & 161 & 0.07 \\
\hline $78-20$ & Eluitkak Pass & $71^{\circ} 21.7^{\prime}$ & $156^{\circ} 21.1^{\prime}$ & Block & 0.82 & 1.36 & 122 & 0.011 & 8 & 181 & 216 & 0.12 \\
\hline $78-21$ & $\mathrm{~S}$ of Plover Pt. & $71^{\circ} 21.6^{\prime}$ & $156^{\circ} 21.7^{\prime}$ & Block & 1.37 & 1.40 & 125 & 0.013 & 9 & 82 & 71 & 0.08 \\
\hline $78-22$ & Elson Lagoon. & $71^{\circ} 18.2^{\prime}$ & $156^{\circ} 05.2^{\prime}$ & Block & $\cdot 0.65$ & 1.57 & 79 & 0.062 & 21 & 137 & 143 & 0.08 \\
\hline $78-23$ & $N$ of Martin Is. & $71^{\circ} 14.3^{\prime}$ & $155^{\circ} 30^{\prime}$ & Block & 0.85 & 1.69 & 70 & 0.013 & 9 & 290 & 286 & 0.06 \\
\hline $78-24$ & Cape Simpson & $71^{\circ} 06.3^{\prime}$ & $154^{\circ} 38^{\prime}$ & Block & 0.65 & 1.35 & 79 & 0.028 & 14 & 138 & 117 & 0.02 \\
\hline $78-25$ & Smith Bay & $70^{\circ} 57.1^{\prime}$ & $154^{\circ} 13^{\prime}$ & Block & 0.87 & 1.73 & 70 & 0.025 & 13 & 268 & 279 & 0.03 \\
\hline $78-26$ & NW of Lonely & $70^{\circ} 57.3^{\prime}$ & $153^{\circ} 22.8^{\prime}$ & Core & $\sim 1.0$ & - & - & - & - & - & - & - \\
\hline $78-27$ & E of Lonely & $70^{\circ} 55.5^{\prime}$ & $152^{\circ} 32^{\prime}$ & Core & 1.70 & 1.70 & - & - & - & - & 288 & 0.06 \\
\hline $78-28$ & Harrison Bay & $70^{\circ} 40.2^{\prime}$ & $151^{\circ} 43^{\prime}$ & Block & 0.70 & 1.66 & 69 & 0.151 & 32 & 46 & 325 & 0.03 \\
\hline $78-29$ & Simpson Lagoon & $70^{\circ} 32^{\prime}$ & $149^{\circ} 29.5^{\prime}$ & Block & 0.65 & 1.68 & 95 & 0.020 & 11 & 240 & 273 & 0.04 \\
\hline $78-30$ & $\mathrm{~N}$ of Pingok Is. & $70^{\circ} 34.6^{\prime}$ & $149^{\circ} 27.3^{\prime}$ & Core & 1.23 & 1.51 & 8 & 0.190 & 37 & 241 & 281 & 0.03 \\
\hline $78-31$ & $\mathrm{~N}$ of Reindeer Is. & $70^{\circ} 32.5^{\prime}$ & $148^{\circ} 19.7^{\prime}$ & Core & $1.43-1.58$ & 1.66 & 29 & 0.019 & 11 & 102 & 121 & 0.01 \\
\hline $78-32$ & Stefansson Sound & $70^{\circ} 25^{\prime}$ & $148^{\circ} 00^{\prime}$ & Block & 0.86 & 1.54 & 79 & 0.024 & 13 & 108 & 121 & 0.02 \\
\hline $78-33$ & $\mathrm{~N}$ of Maguire Is. & $70^{\circ} 15.3^{\prime}$ & $146^{\circ} 27.5^{\prime}$ & Block & 0.88 & 1.82 & 76 & 0.116 & 28 & 107 & 104 & 0.03 \\
\hline $78-34$ & Brownlow Pt & $70^{\circ} 10^{\prime}$ & $145^{\circ} 54.5^{\prime}$ & Block & - & 0.80 & - & - & - & - & - & - \\
\hline $78-35$ & Camden Bay West & $70^{\circ} 08^{\prime}$ & $145^{\circ} 41.3^{\prime}$ & Block & 0.90 & 1.61 & 74 & 0.043 & 17 & 121 & - & 0.00 \\
\hline
\end{tabular}


Table 1 (cont'd.).

\begin{tabular}{|c|c|c|c|c|c|c|c|c|c|c|c|c|}
\hline Site & Location & $\operatorname{Lat}(N)$ & Long $(W)$ & $\begin{array}{c}\text { Sample } \\
\text { type }\end{array}$ & $\begin{array}{c}\text { Sample } \\
\text { depth } \\
(m)\end{array}$ & $\begin{array}{c}\text { lce } \\
\text { thick- } \\
\text { ness } \\
(\mathrm{m})\end{array}$ & $\begin{array}{l}\text { No. of } \\
\text { crystals }\end{array}$ & $\begin{array}{c}S_{*} \\
\text { Circular } \\
\text { variance }\end{array}$ & $\begin{array}{c}s_{\|} \\
S t d \\
\text { dev } \\
\text { (deg) }\end{array}$ & $\begin{array}{c}\bar{X}_{a} \text { Avg. } \\
\text { C-axis } \\
\text { orient } \\
\text { ( }{ }^{\circ} \text { true) }\end{array}$ & $\begin{array}{c}\text { Current } \\
\text { direction } \\
\text { ('true) }\end{array}$ & $\begin{array}{c}\text { Current } \\
\text { speed } \\
(\mathrm{m} / \mathrm{s})\end{array}$ \\
\hline $79-1$ & Barrow (Chukchi) & $71019.4^{\prime}$ & $156^{\circ} 42.5^{\prime}$ & Block & 1.06 & 1.50 & 66 & 0.030 & 15 & 52 & 48 & 0.05 \\
\hline $79-2$ & Barrow (Chukchi) & $71^{\circ} 22.3^{\prime}$ & $156^{\circ} 22.7^{\prime}$ & Block & 0.80 & 1.63 & 61 & 0.014 & 10 & 67 & - & - \\
\hline $79-3$ & $\mathrm{~N}$ of Lonely & $70^{\circ} 56.7^{\prime}$ & $153^{\circ} 16^{\prime}$ & Core & 1.61 & 1.65 & 17 & 0.023 & 12 & 132 & - & - \\
\hline $77-3$ & N of Narwhal is. & $70^{\circ} 29^{\prime}$ & $147^{\circ} 31.7^{\prime}$ & Block & 0.87 & - & 88 & 0.042 & 17 & 38 & - & - \\
\hline $77-4$ & Stefansson Sound & $70^{\circ} 20.2^{\prime}$ & $147^{\circ} 36.5^{\prime}$ & Block & 0.88 & 1.70 & 76 & 0.037 & 16 & 108 & - & - \\
\hline $77-6$ & NW of Narwhal is. & $70^{\circ} 25.1^{\prime}$ & $147^{\circ} 39.3^{\prime}$ & Block & 0.90 & - & 74 & 0.033 & 15 & 96 & - & - \\
\hline $77-7$ & Stefansson Sound & $70^{\circ} 23.7^{\prime}$ & $148^{\circ} 04.3^{\prime}$ & Block & 0.89 & 1.78 & 70 & 0.023 & 12 & 119 & - & - \\
\hline $77-9$ & NE of Stump Is. & $70^{\circ} 26.7^{\prime}$ & $148^{\circ} 29.3^{\prime}$ & Core & 1.02 & - & 20 & 0.073 & 22 & 104 & - & - \\
\hline $77-12$ & $S$ of Stockton Is. & $70^{\circ} 15^{\prime}$ & $147^{\circ} 00^{\prime}$ & Core & 0.91 & - & 18 & $0.009^{\circ}$ & 8 & 144 & - & - \\
\hline $77-14$ & Beaufort Sea & $70^{\circ} 37.7^{\prime}$ & $147^{\circ} 29.7^{\prime}$ & Core & $\sim 1.0$ & - & 10 & 0.049 & 18 & 23 & - & - \\
\hline 77-P14 & W of Stockton Is. & $70^{\circ} 18.8^{\prime}$ & $147^{0} 10.1^{\prime}$ & Core & 0.69 & - & - & - & - & 105 & - & - \\
\hline
\end{tabular}

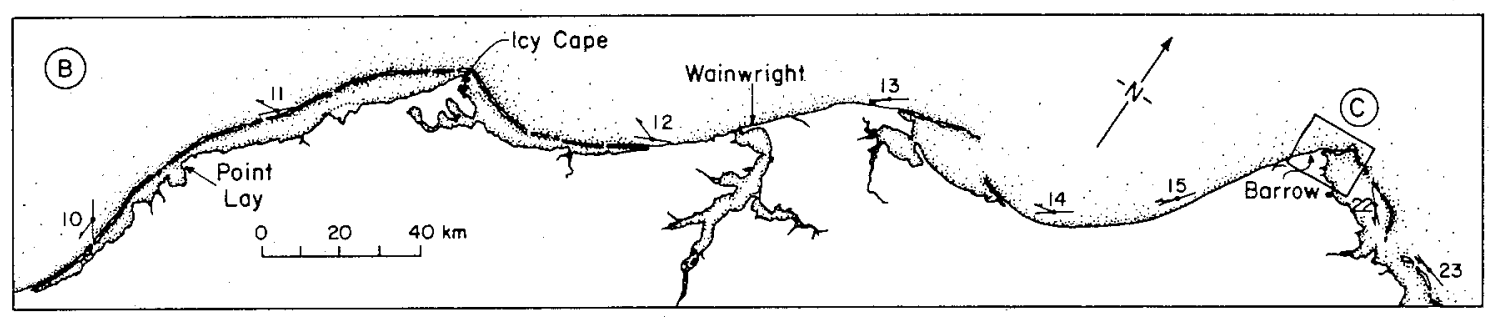

Figure 5. Sample site locations (dots), mean c-axis alignments (bars) and instantaneous current directions (arrows) determined along the Chukchi Sea coast. All sites are 78 sites. 

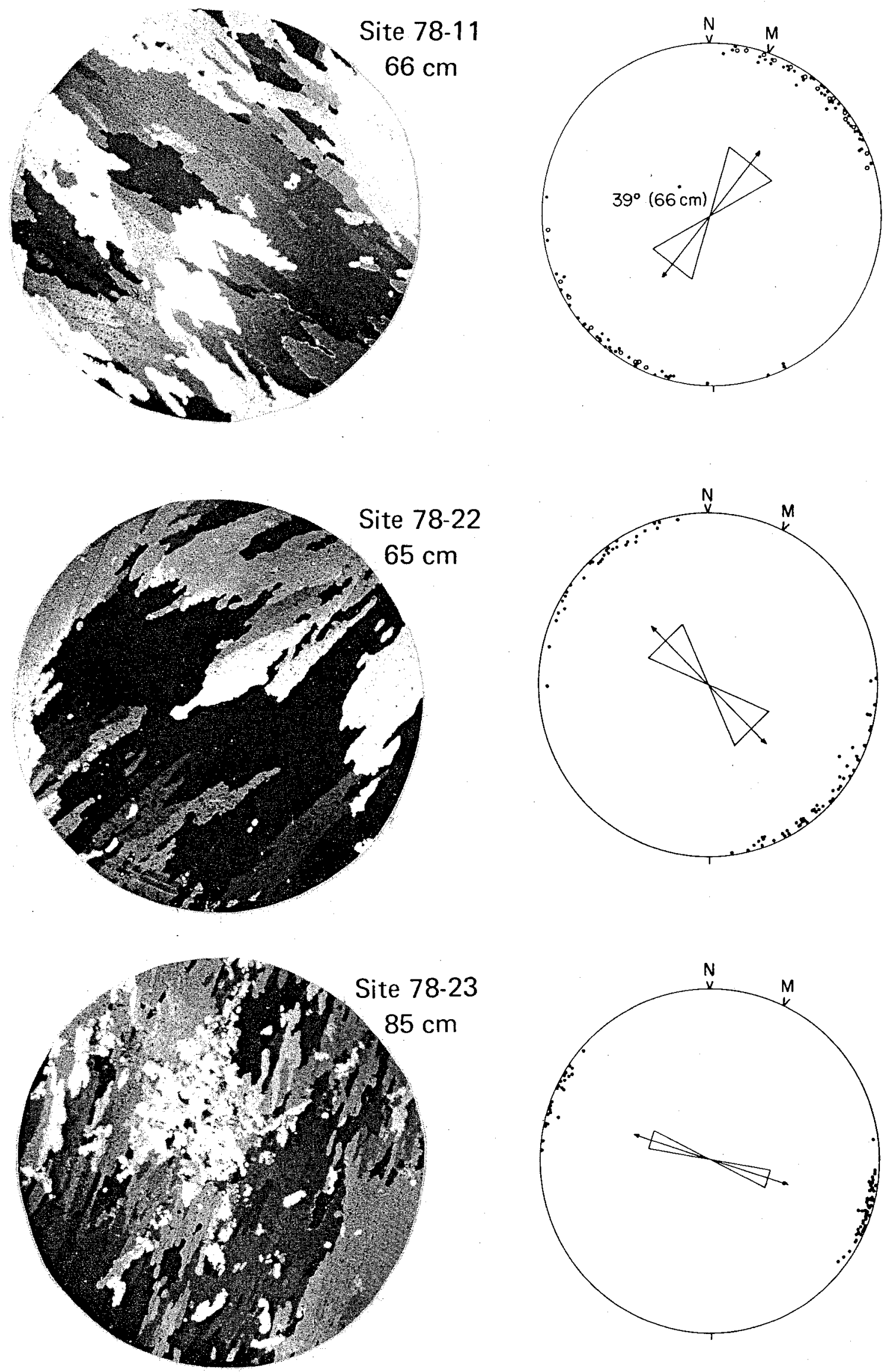


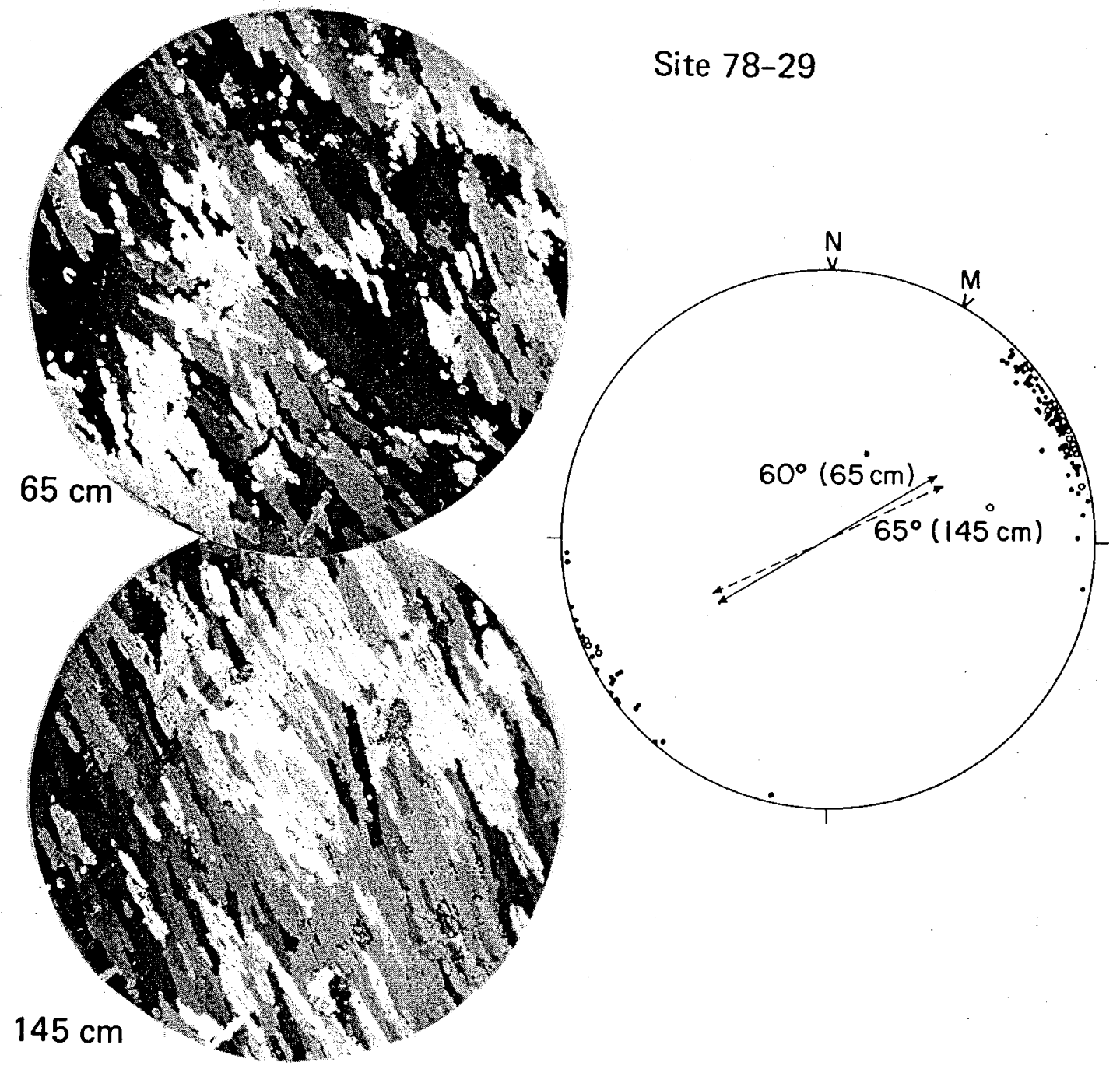

Figure 6. Four representative examples of aligned crystal orientations observed along the coasts of the Chukchi and Beaufort Seas (see Figures 5 and 9 for site locations). At Site 78-11 (southwest of Icy Cape) the fabric diagram shows c-axis orientations from both $66 \mathrm{~cm}$ (dots) and $127 \mathrm{~cm}$ (open circles). The mean directions are similar, $39^{\circ}$ and $43^{\circ}$ respectively. Note the large interfingered crystals at Site 78-22 (Elson Lagoon). At Site 78-23 (north of Martin Island), a brine-drainage structure (the fine-grained feature) can be seen near the center of the thin section. Finally at Site $78-29$ (Simpson Lagoon) note that the mean orientations at 65 and $145 \mathrm{~cm}$ are similar $60^{\circ}$ and $65^{\circ}$, respectively). 
coast at Sites 78-1 and 78-8 located outside Kotzebue Sound. In the entrance to the sound, alignments were parallel to the axis of the entrance (Sites 78-2, 78-6 and 78-7). Within the sound similar orientations are maintained. The overall orientation pattern corresponds to what might be expected for flow in and out of an inlet. The correspondence between mean c-axis directions and instantaneous current directions is generally very good. The differences in current directions between Sites 78-3 and 78-4 may be caused by current reversals associated with the tidal cycle. It should also be noted that the instantaneous currents at Sites $78-8$ and $78-9$ were determined under the fast ice within approximately $100 \mathrm{~m}$ of a large flaw lead during a time when there were unusually strong 35- to 40-knot winds from the northeast. This may account for the "offshore" nature of the currents observed at these two locations.

Figure 5 presents the observations made along the Chukchi Coast between roughly Point Lay and Barrow. The c-axes are aligned parallel to the coast at all but Site 78-10. At this location the situation was somewhat unusual in that there was a large, apparently grounded ice pileup approximately $30 \mathrm{~m}$ north of the sampling site. We suggest that the NW-SE orientation of the c-axes at Site 78-10 is the result of this ice obstacle causing a local deflection of the mean current direction. The c-axis directions and the instantaneous current directions between Point Lay and Barrow are still in reasonable agreement but the agreement is not as good as in the Kotzebue Sound area. Figure 6 , which shows several representative samples of aligned crystal structures observed along the Chukchi and Beaufort Coasts, includes Site 78-11 southwest of Icy Cape. Note that this fabric diagram includes observations made at depths of $66 \mathrm{~cm}$ and 127 $\mathrm{cm}$. The mean directions were nearly the same: $39^{\circ}$ and $43^{\circ}$ respectively.

Figure 7 presents the observations made in the vicinity of Point Barrow. They are particularly interesting. On the Chukchi Sea (west) side of the point, crystal alignments are SW-NE, paralleling the coast and the currents. On the Beaufort Sea (east) side of the point, alignments swing to NW-SE (Site 78-19), presumably reflecting a change in current direction. Perhaps most interesting are sites 78-20 and 78-21. At Site 78-20, located in Eluitkak Pass, the current direction is constrained by the geometry of the pass to NNE-SSW, i.e. almost at right angles to the current direction just to the north in the Beaufort Sea. The observed crystal alignments at Site

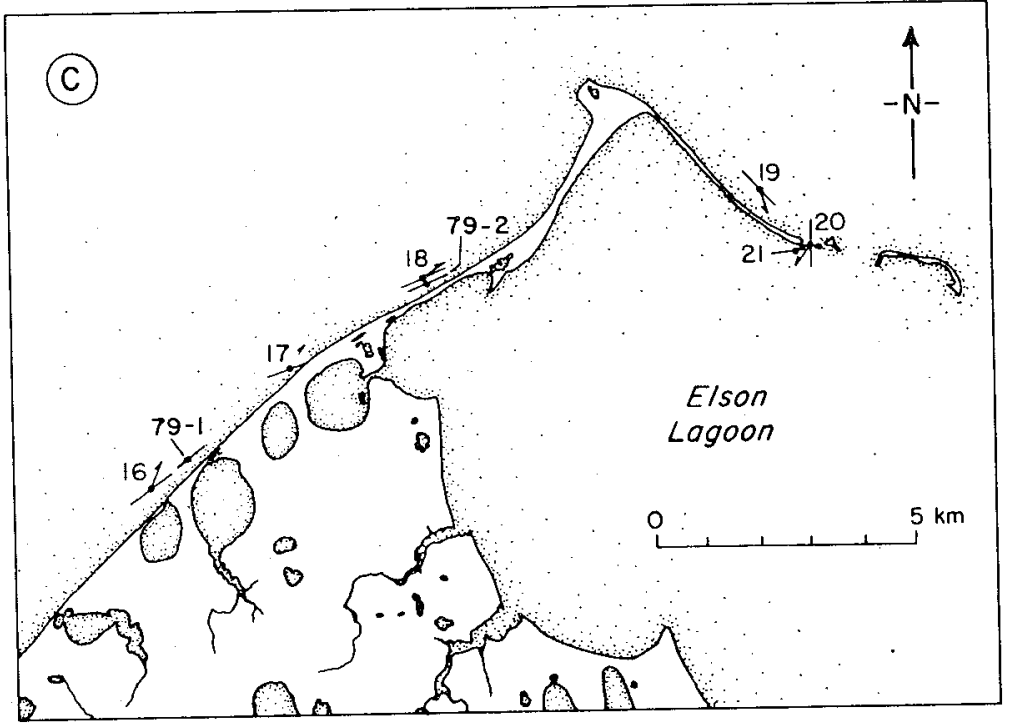

Figure 7. Sample site locations (dots), mean c-axis alignments (bars) and instantaneous current directions (arrows) determined in the vicinity of Point Barrow. All sites were 78 sites unless indicated otherwise. Site 79-1 is, in fact, only $300 \mathrm{~m}$ up the coast from Site 78-16. 
78-20 are in good agreement with the local current direction. At Site 78-21, located just west-southwest of the pass, the crystal alignment has changed to WSW-ENE, reflecting the change in current direction as water passes through the inlet. The changes in current direction between Sites 78-20 (current toward the southwest) and 78-21 (current toward the east-northeast) presumably reflect tidal changes. There are known to be large tidal currents through this pass.

One of the most thoroughly studied sites was Site 78-17, just off the Chukchi coast at the Naval Arctic Research Laboratory where a varety of different measurements were made on the ice in 1978 and 1979. These are described in some detail by Gow et al. (in preparation) and will only be summarized here. The structure of the ice was determined at five different levels $(25,50,88,138$ and $164 \mathrm{~cm})$ using both vertical and horizontal thin sections. After an upper $4 \mathrm{~cm}$ of ice composed of frozen slush, the horizontal $c$-axis fabric developed quite rapidly and a definite crystal alignment was present at $25 \mathrm{~cm}$. By $50 \mathrm{~cm}$ the alignment was very strong and it remained so throughout the rest of the ice sheet. The mean c-axis orientation at $25 \mathrm{~cm}$ was $57^{\circ}$ true, and between 50 and $164 \mathrm{~cm}$ it varied between $72^{\circ}$ and $84^{\circ}$. In short, although all alignments were not identical, at depths of $50 \mathrm{~cm}$ and greater all the orientations were similar.

Site 78-18 was interesting in that we were able to reoccupy the site almost exactly one year later in March 1979 and collect a comparable ice sample (79-2). Figure 8(B) shows the fabric at $78 \mathrm{~cm}$ obtained in April 1978 and the fabric at 80 $\mathrm{cm}$ obtained in March 1979. The mean orientations were effectively identical, $69^{\circ}$ and $67^{\circ}$ respectively. In 1979 we were also able to sample a site (79-1) that was close to, although not identical with, * the location of Site 78-16 (79-1 was approximately $300 \mathrm{~m}$ northwest up the coast from 78-16). These data are presented in Figure 8(A). Again the mean orientation is effectively identical $-55^{\circ}$ and $52^{\circ}$. However, note that at both sites the alignments are less well developed in 1978 than in 1979.

\footnotetext{
* Often it is not possible to reoccupy exact sites as one year the ice at a given location may be undeformed and suitable for sampling while the next year it may be highly deformed.
}

Figure 9 presents the observations made along the coast of the Beaufort Sea. All data shown were collected during 1978 except 79-3 and those sites indicated by the small out-ofsequence numbers shown in the area north and northeast of Prudhoe Bay. These latter values are part of our observational set obtained in 1977 (Weeks and Gow 1978). Also included in Figure 9 are four orientations obtained using radar techniques by Kovacs and Morey (in press) at sites offshore of Cross Island (Sites K1 to K4).

The Beaufort Sea samples can be divided into three sub-sets: those collected within the lagoon systems and just seaward of the barrier islands, those collected along stretches of the coast where barrier islands do not occur (Harrison and Smith Bays and the area north of Lonely), and those obtained appreciably seaward of the barrier islands.

The samples of ice from within the lagoon systems uniformly showed strong c-axis alignments oriented parallel to the trend of the coastline and the long axes of the lagoons. There are only three samples where instantaneous current directions were available. At two of these sites (78-22 and $78-32)$ the mean C-axis direction was in very good agreement with the instantaneous current direction. At the third site (78-29) there was a $33^{\circ}$ difference between the two values. Crystal orientations at sites just offshore from the barrier islands also parallel the general trend of the coastline (e.g. Sites 78-23, 78-24, 78-31, 78-33, 78-35, 77-6). The agreement between mean $\mathrm{c}$-axis direction and instantaneous current direction is also good at these locations. In unprotected bays and in the area near Lonely the situation is not so straightforward. In Smith Bay (Site 78-25) the crystal alignment generally parallels the coast and agrees with the instantaneous current direction. In Harrison Bay (Site 78-28), however, the mean c-axis direction is oriented roughly perpendicular to the trend of the coast and to the instantaneous current direction. The ice at the three sites near Lonely was "odd" and will be discussed below.

The only sites appreciably offshore of the barrier islands in the Beaufort Sea are located north of the Prudhoe Bay area. Of these offshore sites those nearest the coast (77-3, 77-14, K1 and K2) show NNW-SSE c-axis alignments that are quite different in direction from the alignments of the coastal sites (77-4, 77-6, 77-7, 77-9, 77-P14, 78-31, 78-32). The two sites farthest offshore ( $\mathrm{K} 3$ and 
A.

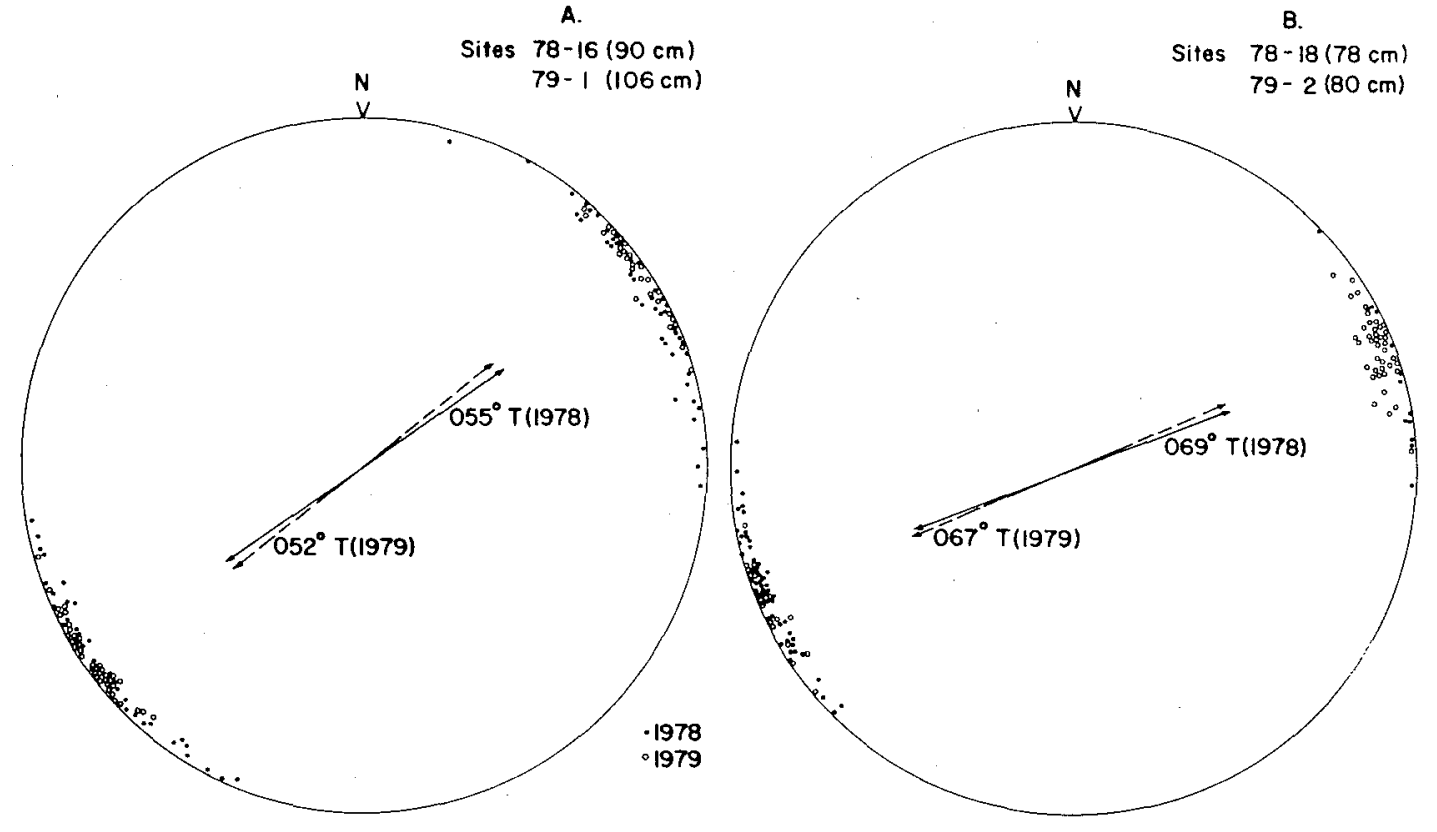

Figure 8. Comparison of crystal orientation data collected in April 1978 (dots) and in March 1979 (open circles) at identical and similar sites along the Chukchi coast near Point Barrow: (A) Site 79-1 was located approximately $300 \mathrm{~m}$ northwest up the coast from Site 78-16 with both sites at similar distances offshore. (B) Sites 78-18 and 79-2 were from the same location (offshore of the NASA site).

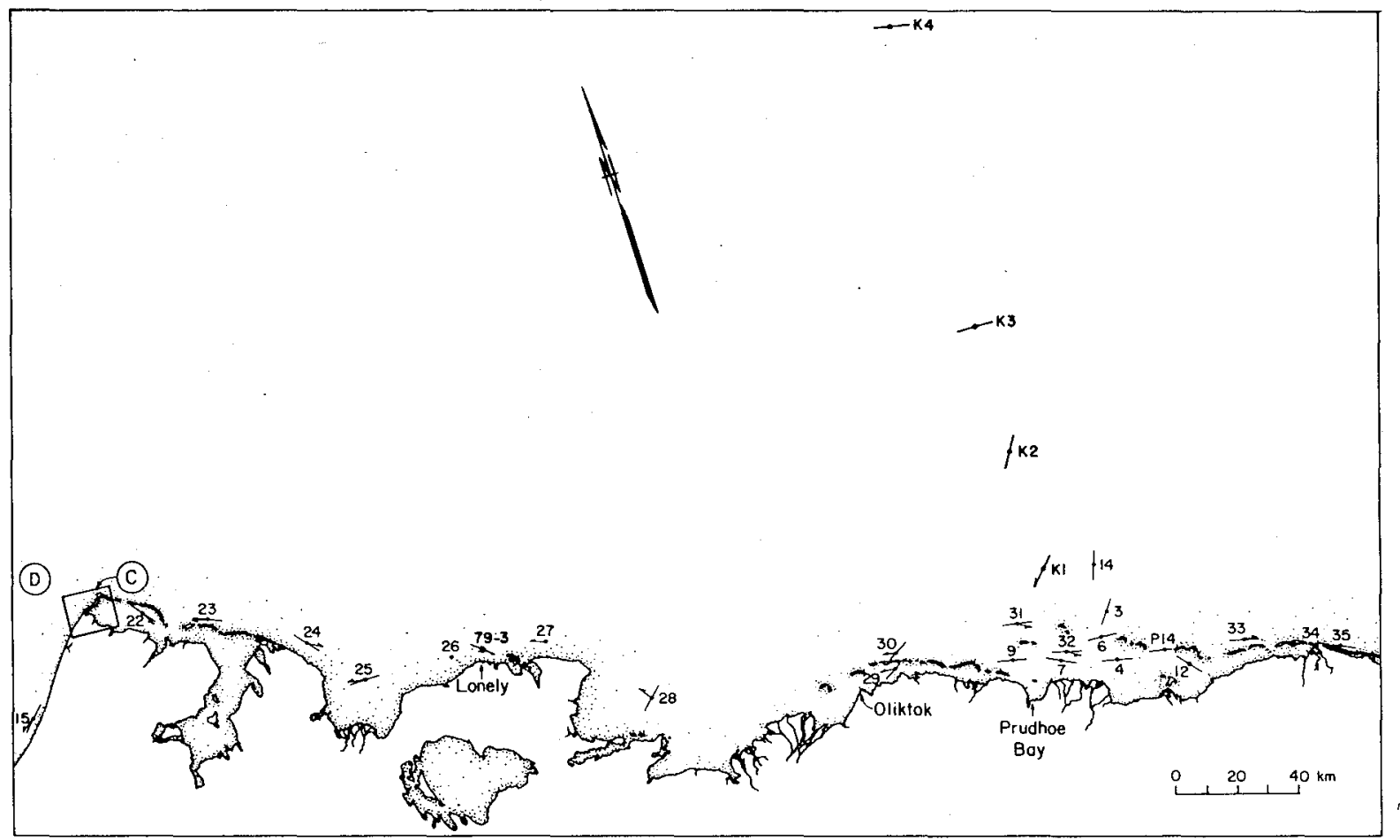

Figure 9. Sample site locations (dots), mean c-axis alignments (bars) and instantaneous current directions (arrows) determined along the coast of the Beaufort Sea. All the samples were collected during 1978 except for Site 79-3 north of Lonely and the low "out-of-sequence" sites $(3,4,6,7,9,12,14$, P14) north of Prudhoe Bay which were collected during 1977 (Weeks and Cow 1978) and are included for comparative purposes. Also shown are four orientations determined by radar (Sites $K 1$ to $K 4$ ) by Kovacs and Morey (in press). 
K4), on the other hand, show an E-W crystal alignment. Of these "offshore" sites only one (K1) is accompanied by an instantaneous current measurement, which was found to be within $5^{\circ}$ of the $c$-axis direction.

\section{"Odd" sites}

Although the general pattern of strong preferred c-axis alignments within the horizontal plane is quite clear, there are exceptions. For instance the weakest fabric observed in the Kotzebue area was at Cape Thompson (Site 78-9). As can be seen in Figure 10, the ice at this site was composed of crystals with a strong c-axis horizontal orientation. However there is no indication of a preferred direction within the horizontal plane. The grain size at this site was generally smaller than observed at sites with aligned ice. The interfingering of crystals commonly observed in aligned ice was also absent, with each crystal occupying a well-defined domain

The other weak alignment in the Kotzebue area is from Site 78-7 located just west of Sheshalik (see Fig. 2). Within the horizontal plane- the--alignment is weak but nevertheless still clearly present, with the mean c-axis direction paralleling what would be expected to be the mean current direction parallel to the axis of the inlet. (The instantaneous current at this site was too low to measure.) This site is also unusual in that the ice salinities are both low (2 to $3 \%$ ) as contrasted with typical fast ice salinities in the same general region (5 to $11 \%$ ) and show a general decrease from the top of the ice sheet to the bottom. This is presumably caused by the influx of fresh water from the Noatak River, which causes a layer of low salinity water to gradually develop just beneath the ice cover once the ice cover has formed and the possibility of windinduced mixing has disappeared.

Along the portion of the Chukchi coast shown in map B (Fig. 5) Site 78-10 shows a C-axis alignment that is inclined at quite a high angle (about $50^{\circ}$ ) to the trend of the coast. As mentioned earlier, this is believed to be produced by the deflection of the mean current direction by a large grounded ice pile-up located just north-northwest of the sampling site. Another set of interesting fabrics was observed at Site 78-12 located southwest of Wainwright. The c-axis orientations at $74 \mathrm{~cm}$ and at $143 \mathrm{~cm}$ are shown in Figure 10 . The alignment at $74 \mathrm{~cm}$ is not particularly strong and both alignments differed appreciably $\left(37^{\circ}\right.$ and $50^{\circ}$ ) from the measured current direction.
Other "different" locations are Site 78-28 in Harrison Bay, Site 78-30 north of Pingok Island, and Site 78-31 north of Reindeer Island. Fabrics from all these locations are also shown in Figure 10. At Harrison Bay the c-axis alignment is poorly developed and the mean c-axis direction differs significantly $\left(81^{\circ}\right)$ from the instantaneous current direction as well as from the general trend of the coastline. The upper $18 \mathrm{~cm}$ of ice contained an appreciable amount of dirt. North of Pingok Island, fabrics were made at two levels in the ice sheet. The c-axes shown as solid circles were from ice obtained at $66 \mathrm{~cm}$ depth. They show no preferred alignment within the horizontal plane and even the c-axis horizontal orientation is weak. The fabric denoted by open circles was obtained from ice from a depth of $123 \mathrm{~cm}$ and shows only a moderate c-axis alignment within the horizontal plane which differs by about $40^{\circ}$ from the measured instantaneous current direction. At Site 78-31, north of Reindeer Island, the ice from $65 \mathrm{~cm}$ is similar to the ice at $66 \mathrm{~cm}$ observed north of Pingok Island in that the grain size was quite small and there was no preferred c-axis alignment in the horizontal plane. Although a $\mathrm{c}$-axis horizontal girdle was clearly present, it too was not as sharply developed as is usually the case at this depth in the ice sheet. At $143 \mathrm{~cm}$ depth the crystals are much larger and they show a strong $\mathrm{c}$-axis alignment within the horizontal plane which is oriented within $20^{\circ}$ of the measured instantaneous current direction.

The most unusual ice encountered was at Sites 78-26 and 78-27 located along the Beaufort Sea coast north of Lonely. At Site 78-27 the upper $130 \mathrm{~cm}$ of ice was very fine grained $<2$ $\mathrm{mm}$ ) and as best as could be ascertained by visual examination showed a completely random orientation (the grain size was below that required for the effective use of a Rigsby stage). There was also a considerable amount of dirt uniformly dispersed through the ice. This same ice type was found to a depth of $1 \mathrm{~m}$ at Site 78-26, where sampling was terminated, and to a depth of $87 \mathrm{~cm}$ at Site $78-19$ at Point Barrow. We suggest that this ice originated as a thick slush layer that developed along exposed portions of the coast such as at Lonely. The wave action that would cause the slush formation would introduce large amounts of suspended sediment into the water and ultimately into the ice cover. It should also be noted that a large number of grounded ridges were present just offshore of 

these sampling sites and that they showed large quantities of sediment in their sails, indicating that there had also been appreciable plowing of the bottom during the formation of the fast ice cover. This would also contribute to the amount of sediment incorporated in the ice. At Site 78-19 a strong horizontal c-axis alignment developed in the congelation ice that formed beneath the "slush" layer. At Site 78-27, on the other hand, there was no development of such an alignment in the congelation ice although a strong $\mathrm{c}$-axis horizontal orientation was observed.

In March 1979 we returned to the area north of Lonely to see if we would encounter similar ice types. This was not the case (Fig. 11). The ice encountered approximately $3 \mathrm{~km}$ due north of Lonely (Site 79-3) was normal dirt-free congelation ice that showed a strong $\mathrm{c}$-axis horizontal orientation but no pronounced $\mathrm{c}$-axis alignment within the horizontal plane at a depth of $65 \mathrm{~cm}$. At 115 and at $135 \mathrm{~cm}$ it is as if two different orientations coexist. Unfortunately, because these samples were obtained from cores, not enough crystals were measured to provide definitive patterns. At $161 \mathrm{~cm}$ a strong $\mathrm{c}$-axis alignment was finally observed. Its mean $\mathrm{c}$-axis direction was $132^{\circ}$, which is roughly $25^{\circ}$ from parallel to the local coastline.

In short, our observations of crystal orientations in the fast ice along the coast of arctic Alaska show that although strong c-axis alignments within the horizontal plane are the common case, several other types of ice fabrics do occur. For instance there may be no preferred orientation within the horizontal girdle. The girdle may also not be strongly developed, with some crystals departing significantly from a caxis horizontal orientation. In two cases (Sites 78-26 and 78-27), the majority of the ice sheet (at least to $1 \mathrm{~m}$ ) was composed of very small crystals that "appeared" to have no preferred orientation (a completely isotropic fabric). However, because of the small grain size it was not possible to perform a fabric analysis and there may be some slight tendency for a horizontal c-axis alignment even in this ice.

All of these structural and textural changes within the ice provide us with information concerning the growth conditions at the time each level of the ice sheet formed. Unfortunately, at the present time only a small percentage of this frozen library of information is decipherable.

\section{CAUSES}

In an earlier paper (Weeks and Gow 1978) we discussed in some detail the possible causes of the strong $\mathrm{c}$-axis alignments observed in sea ice. We rejected the suggestion of Cherepanov (1971) that the earth's magnetic field was the controlling factor and pointed out that the alignments could be explained by the effect that fluid flow (currents) would have on the relative growth rates of crystals in different orientations. If the current flows perpendicular to the tips of the "forest" of ice platelets that compose the growing interface of a sea ice crystal (i.e. flow parallel to the c-axis), this enhances the mixing in the boundary layer and reduces the build-up of impurities (salt) at the interface. This reduced impurity build-up causes the interface freezing temperature of such crystals to be very slightly higher than the interface freezing temperature of similar crystals in less favorable orientations relative to the current. The crystals with the higher interface temperatures are able to grow slightly ahead of the surrounding, less favored crystals, and gradually expand their territory at the interface. This ultimately eliminates the less favored crystals by cutting them off from contact with the melt.

Although the field observations presented here do not contribute to our understanding of the mechanistic details of exactly how c-axis alignments develop, they do reinforce our view that it is the current direction at the ice/water interface that controls the direction of the c-axis alignment. For instance Figure 12(A) summarizes the available information on the correspondence between c-axis alignments and instantaneous current measurements. The most common deviation between the mean c-axis direction and the instantaneous current direction is less than $10^{\circ}$, with the frequency of occurrence decreasing rapidly as the angular deviation increases. We consider this agreement to be excellent in that short-term current measurements are known to commonly show significant deviations from the long-term average current direction as the result of eddies. This is particularly true at sites farther from the coast where the effects of topographic steering are less. Also shown in Figure $12(B)$ is a plot of the data on the correspondence between $c$-axis alignments and the trend of the neighboring coastline for all sites 

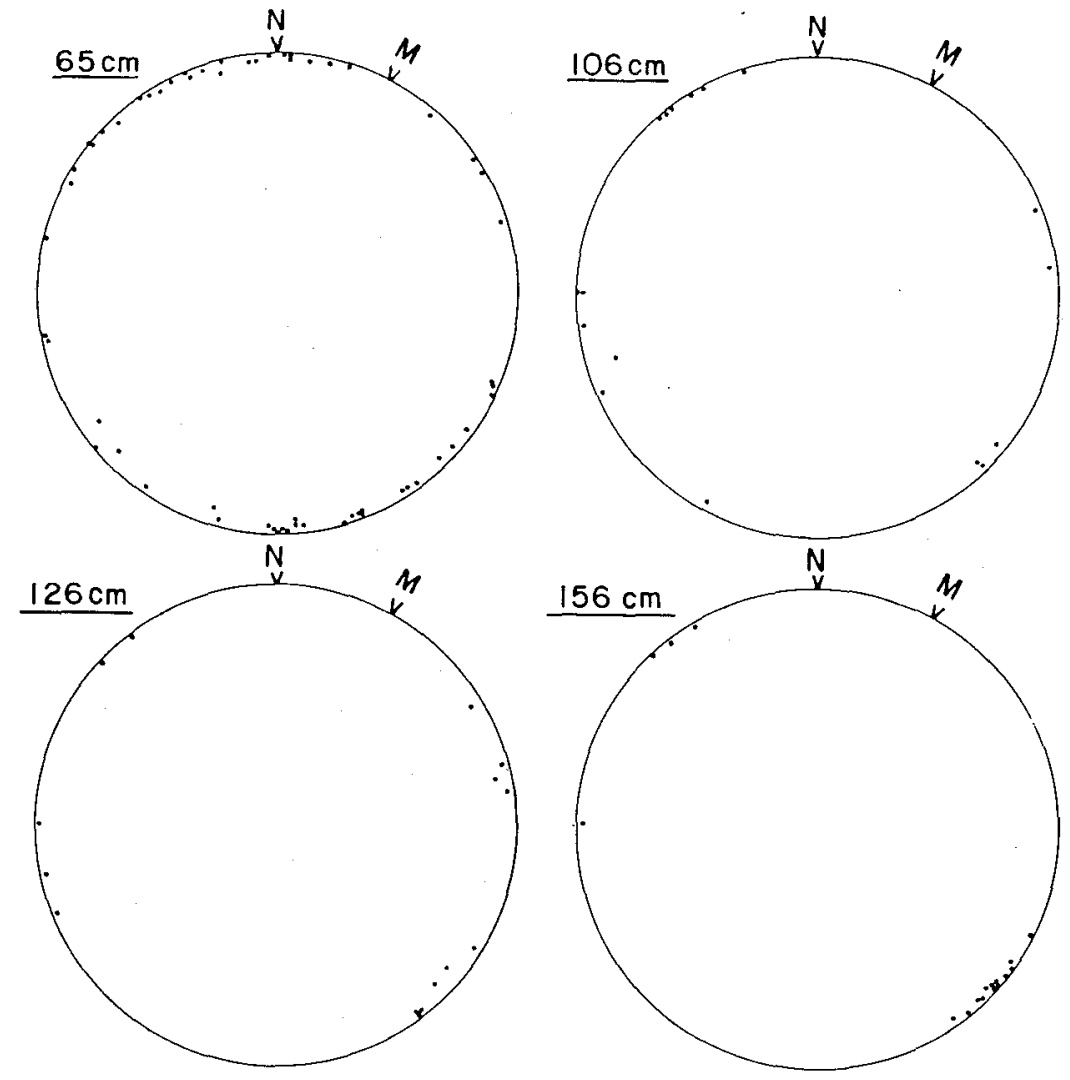

Figure 11. Schmidt net plots of individual c-axis orientations at Site 79-3, located approximately $3 \mathrm{~km}$ offshore due north of Lonely.

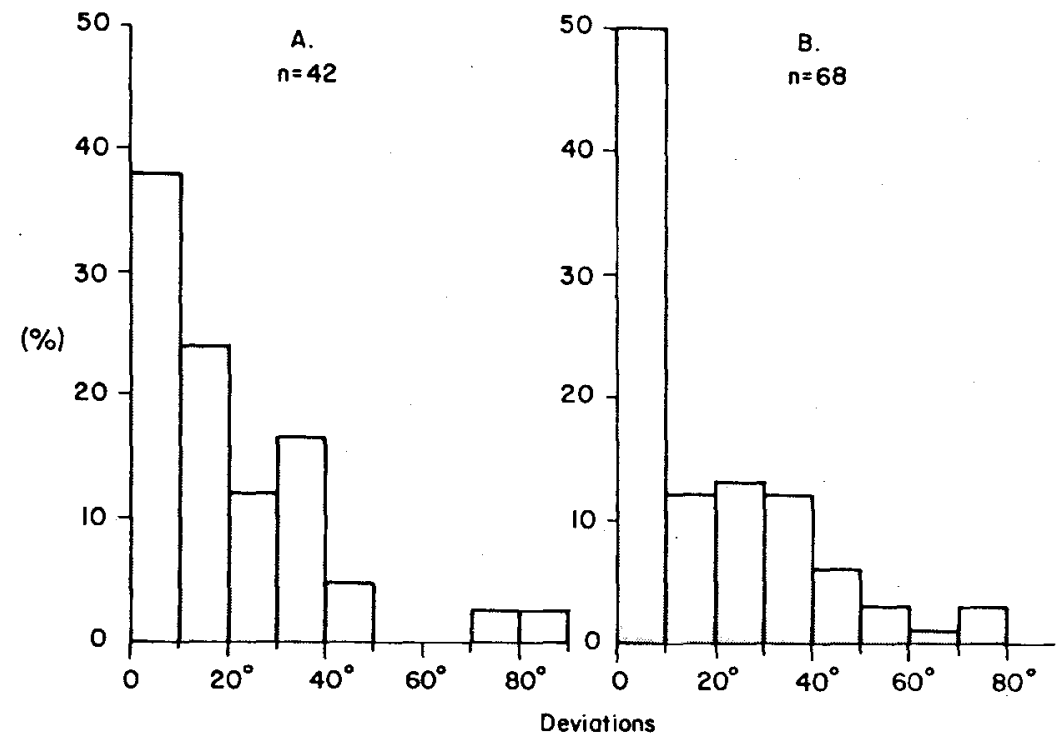

Figure 12. Histograms showing the relative frequency of different deviations between: (A) the observed "instantaneous" current direction and the mean c-axis direction and $(B)$ the trend of the adjacent coastline and the mean c-axis direction. Data taken from the present paper, Weeks and Gow (1978) and Kovacs and Morey (in press; 1978). 
located within the near-shore regime. In preparing this figure we used all available data with the exception of offshore sites in the Beaufort Sea (i.e. Sites 78-3, 78-14, K1, K2, K3 and K4). Note that in $52 \%$ of the observations, the mean c-axis direction was within $10^{\circ}$ of paralleling the coastline. (Selecting an appropriate coastline direction is, in some cases, a bit subjective. When sites were near islands the coast of the island was utilized, in passes the axis of the channel, and at a few questionable locations the trend of the bottom topography.) We chose the alignment of the coastline because in a nearshore regime, and particularly in a near-shore regime showing the extensive development of barrier islands, the direction of the coastline is an excellent index of the direction of the dominant longshore currents that cause the islands to form (Short 1979).

At the present time only six ice sites that lie offshore of the near-shore regime have been studied along the Alaskan coast. Of these six sites, all of which lie north of Prudhoe Bay, four are located over the inner shelf and two over the outer shelf, which have been taken to be bounded by the water depths of 10 to $50 \mathrm{~m}$ and $50 \mathrm{~m}$ to the shelf break respectively (Aagaard 1978). The ice sites over the inner shelf $(77-3,77-14, K 1$ and $\mathrm{K} 2)$ give $\mathrm{c}$-axis alignments oriented NE-SW $\left(38^{\circ}\right.$, $23^{\circ}, 40^{\circ}$ and $30^{\circ}$ respectively). Note that the general alignment directions shown by our observations and by those of Kovacs and Morey (in press) are in good agreement. Note also that these alignment directions are quite different, by approximately $70^{\circ}$, from those of the near-shore regime just to the south. Winter current meter observations over the inner shelf in the vicinity of these sample sites are rare. Kovacs and Morey (in press) report an instantaneous current direction within $5^{\circ}$ of their estimated $\cdot \mathrm{c}$-axis direction. There are only two long-term winter current measurements (Aagaard and Haugen 1977) determined for a $3 \frac{1}{3}$-week period in March and April 1976 with which the inner shelf ice orientations can be compared. A discussion of these results can be found in both the original reference and in Weéks and Cow (1978). The 10-m mean motions were small and were directed toward $240^{\circ}$ and $248^{\circ}$ true. If we subtract $24^{\circ}$ from these values in order to estimate the current direction at the ice/water interface (a correction for the Ekman spiral in the oceanic boundary layer) we obtain $220^{\circ}$ which is in good agreement with the observed mean c-axis orientation of the four sites of $213^{\circ}(33+180)$. In short, in the inner shelf the c-axis alignments and the limited winter current information show good correspondence.

Further seaward over the outer shelf, there are only two ice sites and no nearby current measurements (either instantaneous or longer-term) with which ready comparisons can be made. Available data farther to the west off Oliktok, again collected by Aagaard and Haugen (1977), indicate oscillating flows along the general line $100^{\circ}-280^{\circ}$ which is parallel to the local isobath trend and is presumably the result of bathymetric steering. This orientation is again in excellent agreement with the observed mean $c$-axis directions at the two sites of $90^{\circ}$ and $100^{\circ}$. It also should be noted that over the outer shelf the general ice drift is known to be from the east toward the west, paralleling the edge of the shelf break. This ice drift would result in an apparent easterly current even if the ocean itself was motionless.

In summary, as we move off the coast in the Prudhoe Bay area the crystal alignments change from an average direction of $106^{\circ}$ near shore, to $33^{\circ}$ over the inner shelf, to $100^{\circ}$ over the outer shelf. These changes correspond almost exactly to the best estimates for the current directions in the same areas as summarized by Aagaard (1978). We believe this agreement to be far too good to be coincidence, particularly considering the large changes in direction that are involved and the consistency in direction within a given area.

One additional result should now be added. On 1 April 1979 we were able to obtain continuous current observations in the vicinity of the ice/water interface at Site 79-1 on the Chukchi coast near Point Barrow. The length of the record was 7 hours (0100 to 0800 AST). We had initially hoped to obtain a much longer record, but we encountered pronounced interference problems caused by the local radio station which required us to collect data only when the station was off the air. A histogram giving the 5 -minute current directions is shown as Figure 13. The mean current direction was $48^{\circ}$, which is exactly parallel to the local coastline. The mean $c$-axis alignment determined on cores of the bottom of the ice sheet was $52^{\circ}$, in very good agreement. At an OCS diving operation located roughly $300 \mathrm{~m}$ northeast up the coast from Site 


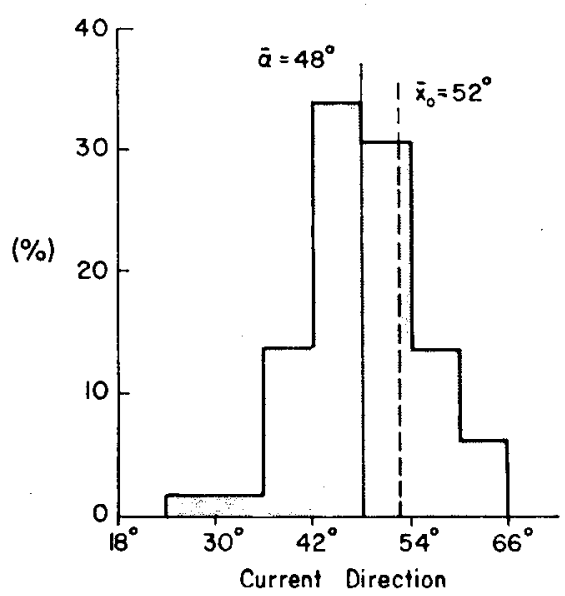

Figure 13. Histogram showing the relative frequency of different current directions obtained at Site 79-1 off Barrow along the Chukchi coast. The average current direction $\alpha=48^{\circ}$ and the average $\mathrm{c}$-axis direction $\left(\bar{X}_{a}\right)=52^{\circ}$ are indicated.

79-1, the divers reported that although the strength of the current varied considerably and appeared to be highest when the flaw lead along the Chukchi coast was open, the current direction was always along the coast toward the northeast. The same divers reported strong crystal alignments in the ice surrounding their dive site, with the c-axes paralleling the coast.

When we couple these observations with the general results on alignment directions within the near-shore regime along the whole coast of arctic Alaska [i.e. general parallelism with the coast, systematic "streamline" deflections around islands (see Weeks and Gow 1978), and alignments parallel to the axes of restricted channels] and add the results obtained in the Kara Sea by Cherepanov (1971) which can be interpreted in a similar manner (Weeks and Gow 1978), we conclude that there is excellent observational support for the hypothesis that the current direction at the ice/water interface is the controlling factor in determining the direction of the horizontal $\mathrm{c}$-axis alignment in the ice with the c-axes paralleling the current. There are, of course, oddities and even rare apparent exceptions. However this is geophysics, a subject in which $100 \%$ agreement can be a very elusive goal. We believe that it is quite possible that the oddities and exceptions could also be rationalized within the "current" hypothesis if information was available giving details of the growth history of the ice.. However this is not the case.
Finally we would like to point out that the alignments noted at the sites off the coast (77-14, $K 1, \ldots, K 4)$ reinforce Cherepanov's observations that strong crystal alignments can develop in areas of pack ice. The restriction here is probably that ice motions, and particularly floe rotations, are small enough that the orientation between the ice and the underlying current field remains reasonably constant long enough for a crystal alignment to develop.

\section{CONCI.USIONS}

We have now completed a reasonably thorough survey of c-axis orientations in the fast ice along the margins of the Chukchi and Beaufort Seas. Although the sampling was sparse considering the large areas of ice that were surveyed, the results were quite consistent, allowing the following general statements to be made.

1. In all the ice studied that was formed by unidirectional freezing, $\mathrm{c}$-axis horizontal orientations develop rapidly after an initial ice skim forms and they dominate the rest of the ice growth.

2. In over $95 \%$ of this ice, strong c-axis alignments also develop within the horizontal plane (representative standard deviations around the mean are commonly less than $10^{\circ}$ for ice collected from near the bottom of ice sheets in excess of $1.5 \mathrm{~m}$ thick). Alignments may be present in ice $20 \mathrm{~cm}$ thick and they invariably become stronger with increasing depth in the ice

3. Although the c-axis direction $\left(\bar{X}_{0}\right)$ is not constant at different levels in the ice sheet, the variations are commonly less than $20^{\circ}$ and do not usually show significant trends.

4. Mean $c$-axis directions at the same site appear to be similar from year to year; however the "strength" of the alignment may vary.

5. The alignment patterns are as follows:

a. In the near-shore regime, the $c$-axes generally parallel the coast, swing around islands in a streamline-like pattern, and are aligned parallel to the axes (throats) of passes and inlets.

b. Over the inner shelf (data for Beaufort Sea only), alignments show a NE-SW orientation.

c. Over the outer shelf (again data only for Beaufort Sea) alignments shift to $E-W$.

6. Alignment directions are in excellent agreement with simultaneous current measurements 
at the 42 sites where such observations are available and with best estimates of local current directions at sites where they are not.

7. Strong crystal alignments can also develop in areas of pack ice provided the ice is sufficiently constrained to prevent large floe rotations relative to the direction of the current.

The overall agreement between mean c-axis directions and observed or inferred current directions is sufficiently good that it, in our opinion, further supports our earlier hypothesis (Weeks and Cow 1978) that it is the current direction at the ice/water interface that is the controlling factor in determining the c-axis direction. Nevertheless this hypothesis is still far from proven and the physics of the current-orientation interaction is still largely speculation. However one can at least suggest how such an interaction might work within the bounds of existing crystal growth theory. As of the present time we have not encountered another hypothesis that we would judge to be plausible for the control of such alignments. Certainly such alignments must be considered to be a reality in the study of sea ice (we have recently heard informally that similar alignments have now been encountered north of the Mackenzie Delta, within the Canadian Archipelago, and along the Antarctic Coast). As we feel that it will prove difficult to resolve many aspects of this problem in the field, we now plan to initiate a series of laboratory experiments which we hope will provide us with further insight in these matters.

\section{LITERATURE CITED}

Aagaard, K.(1978) Physical oceanography and meteorology, In Environmental Assessment of the Alaskan Continental Shelf, Interim Synthesis: Beaufort/Chukchi, NOAA, Environmental Research Laboratories, Boulder, Colorado, 56-100.

Aagaard, K. and D. Haugen,(1977) Current measurements in possible dispersal regions of the Beaufort Sea, In Environmental Assessment of the Alaskan Continental Shelf, Vol. 4, Principal Investigators Reports, Jan - Mar 1977, U.S. Department of Commerce/U.S. Department of the Interior, Washington, D.C.

Cherepanov, N.V.(1971) Spatial arrangement of sea ice crystal structure (in Russian). Probl. Arktiki i Antarktiki, vol.38, p. 137-140.

Coachman, L.K., K. Aagaard and R.B. Tripp (1975) Bering Strait: The regional physical oceanography. Univ. of Washington Press, Seattle.

Gow, A.J., W.F. Weeks, G. Olhoeft, H. Kohnen, M. Aota, T. Tabata, L. Shapiro, R. Metzner, R. Onstott and R.K. Moore (in prep.) Interrelations between the internal structure and the physical properties of fast sea ice at Barrow, Alaska. U.S. Army Cold Regions Research and Engineering Laboratory, CRREL Report.

Kovacs, A. and R.M. Morey(1978) Radar anisotropy of sea ice due to preferred azimuthal orientation of the horizontal c-axes of ice crystals. Journal of Ceophysical Research, vol. 83, no. 12, p. 6037-46

Kovacs, A. and R.M. Morey (in press) Anisotropic properties of sea ice in the $50-150 \mathrm{MHz}$ range. Journal of Ceophysical Research.

Short, A.D. (1979) Barrier island development along the Alaska-Yukon coastal plains. Bulletin of the Geological Society of America, vol. 90, part 11, p. 77-103.

Weeks, W.F. and A.j. Gow (1978) Preferred crystal orientations in the fast ice along the margins of the Arctic Ocean, Journal of Ceophysical Research, vol. 83, no. C 10 , p. $5105-21$. 


\section{APPENDIX A. CURRENT OBSERVATIONS}

Inasmuch as winter current measurements under the ice along the north coast of Alaska are virtually nonexistent, we would like to briefly comment on our results in this area. All observations were "instantaneous" and were made using a Marsh-McBirney electromagnetic current meter. The measurements were taken roughly 20 to $40 \mathrm{~cm}$ below the ice. The data are tabulated in Table 1. Current speeds were uniformly low 1 to $8 \mathrm{~cm} / \mathrm{s}$ ). The one exception to this was $12 \mathrm{~cm} / \mathrm{s}$ observed in Eluitkak Pass (Site 78-20).

In the Kotzebue Sound area the current off Shishmaref (Site 78-1) was toward the southwest. Although the general flow in this part of the Chukchi Sea is toward the north, indication of the existence of such a coastal countercurrent can be found in Coachman et al. (1975, Fig. 85). Along the coast northwest of Kotzebue (Sites 78-8 and 78-9) currents were toward the southsouthwest and inclined at a good angle to the? coast. The currents offshore here are generally believed to be northerly. We are inclined to attribute the direction of the instantaneous currents here to the strong northeasterly wind (35 to
40 knots) that occurred while these readings were being obtained.

Along the Chukchi coast between Sites 78-10 and 78-15 (see Fig. 5) all currents were toward the west-southwest, down the coast. This countercurrent contrasts with the generally northeasterly flow encountered farther off the coast (see Coachman et al. 1975) and with the direction of near-shore sediment transport as deduced from studies of the offshore bars (Short 1979). It is only near Barrow (Sites 78-16 to 78-18) that northeasterly currents were encountered.

In the Beaufort Sea the near-shore currents show values oriented both westerly and easterly along the coast. There is no simple pattern apparent. Based on summer observations and sediment transport studies, the general near-shore currents during the summer months are believed to be westerly. Probably the most interesting observations are the current measurements at Site $\mathrm{K} 1$, and the crystal alignments at Sites 77-3, 77-14 and $K 1$ to $K 4$, which suggest that during the winter the currents over the inner shelf are southwesterly and those over the outer shelf are oriented parallel to the general trend of the shelf break. 
A facsimile catalog card in Library of Congress MARC format is reproduced below.

Weeks, W.F.

Crystal alignments in the fast ice of arctic Alaska / by W.F. Weeks and A.J. Gow. Hanover, N.H.: U.S. Cold Regions Research and Engineering Laboratory; Springfield, Va.: available from National Technical Information Service, 1979 .

v, 25 p., illus.; 27 cm. ( CRREL Report 79-22.)

Prepared for National Science Foundation and National Oceanic Atmospheric Administration by Corps of Engineers, U.S. Army Cold Regions Research and Engineering Laboratory under NSF-DPP 77-27479 and NOAA Order 01-5-022-1651. Bibliography: p. 19 .

Weeks, W.F.

Crystal alignments in the fast ice... 1979

(Card 2)

1. Beaufort Sea. 2. Chukchi Sea. 3. Crystal growth. 4. Crystal structure. 5. Ice. 6. Pack ice. 7. Sea ice. I. Gow, A.J., joint author. II. United States. Army. Corps of Engineers. III. Army Cold Regions Research and Engineering Laboratory. IV. Series: CRREL Report 79-22. 